This item was submitted to Loughborough's Research Repository by the author.

Items in Figshare are protected by copyright, with all rights reserved, unless otherwise indicated.

\title{
NMR spectral analysis of second-order 19F-19F, 19F-1H and 13C-19F coupling constants in pentafluorobenzene and tetrafluoro-4- (morpholino)pyridine using ANATOLIA
}

\section{PLEASE CITE THE PUBLISHED VERSION}

https://doi.org/10.1016/j.jfluchem.2019.04.018

\section{PUBLISHER}

(C) Elsevier BV

\section{VERSION}

AM (Accepted Manuscript)

\section{PUBLISHER STATEMENT}

This paper was accepted for publication in the journal Journal of Fluorine Chemistry and the definitive published version is available at https://doi.org/10.1016/j.jfluchem.2019.04.018.

\section{LICENCE}

CC BY-NC-ND 4.0

\section{REPOSITORY RECORD}

Edgar, Mark, Fatemeh Zeinali, Mariam Mojally, Charlotte Hughes, Shahzad Riaz, and George Weaver. 2019. "NMR Spectral Analysis of Second-order 19F-19F, 19F-1H and 13C-19F Coupling Constants in Pentafluorobenzene and Tetrafluoro-4-(morpholino)pyridine Using ANATOLIA". Loughborough University. https://hdl.handle.net/2134/37825. 


\section{Accepted Manuscript}

Title: NMR Spectral Analysis of Second-Order ${ }^{19} \mathrm{~F}-{ }^{19} \mathrm{~F}$, ${ }^{19} \mathrm{~F}-{ }^{1} \mathrm{H}$ and ${ }^{13} \mathrm{C}-{ }^{19} \mathrm{~F}$ Coupling Constants in Pentafluorobenzene and Tetrafluoro-4-(morpholino)pyridine using ANATOLIA

Authors: Mark Edgar, Fatemeh Zeinali, Mariam Mojally, Charlotte Hughes, Shahzad Riaz, George W. Weaver

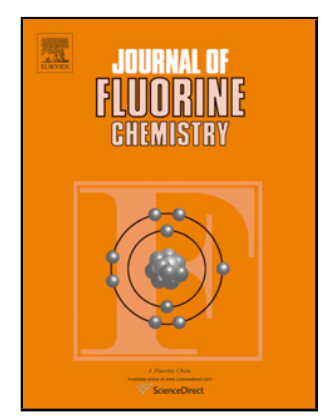

PII: S0022-1139(18)30509-8

DOI: https://doi.org/10.1016/j.jfluchem.2019.04.018

Reference: FLUOR 9321

To appear in: FLUOR

Received date: $\quad 20$ December 2018

Revised date: $\quad 24$ April 2019

Accepted date: $\quad 25$ April 2019

Please cite this article as: Edgar M, Zeinali F, Mojally M, Hughes C, Riaz S, Weaver GW, NMR Spectral Analysis of Second-Order ${ }^{19} \mathrm{~F}-{ }^{19} \mathrm{~F},{ }^{19} \mathrm{~F}-$ ${ }^{1} \mathrm{H}$ and ${ }^{13} \mathrm{C}-{ }^{19} \mathrm{~F}$ Coupling Constants in Pentafluorobenzene and Tetrafluoro-4(morpholino)pyridine using ANATOLIA, Journal of Fluorine Chemistry (2019), https://doi.org/10.1016/j.jfluchem.2019.04.018

This is a PDF file of an unedited manuscript that has been accepted for publication. As a service to our customers we are providing this early version of the manuscript. The manuscript will undergo copyediting, typesetting, and review of the resulting proof before it is published in its final form. Please note that during the production process errors may be discovered which could affect the content, and all legal disclaimers that apply to the journal pertain. 
NMR Spectral Analysis of Second-Order ${ }^{19} \mathrm{~F}^{19}{ }^{19},{ }^{19} \mathrm{~F}-{ }^{1} \mathrm{H}$ and ${ }^{13} \mathrm{C}-{ }^{19} \mathrm{~F}$ Coupling Constants in Pentafluorobenzene and Tetrafluoro-4-(morpholino)pyridine using ANATOLIA.

Mark Edgar, ${ }^{*}$ Fatemeh Zeinali, Mariam Mojally, Charlotte Hughes, Shahzad Riaz and George W. Weaver.

Department of Chemistry, Loughborough University, Loughborough, Leicestershire, LE11 3TU, England, UK.

Corresponding author: $\underline{\text { m.edgar@lboro.ac.uk }}$

Graphical abstract

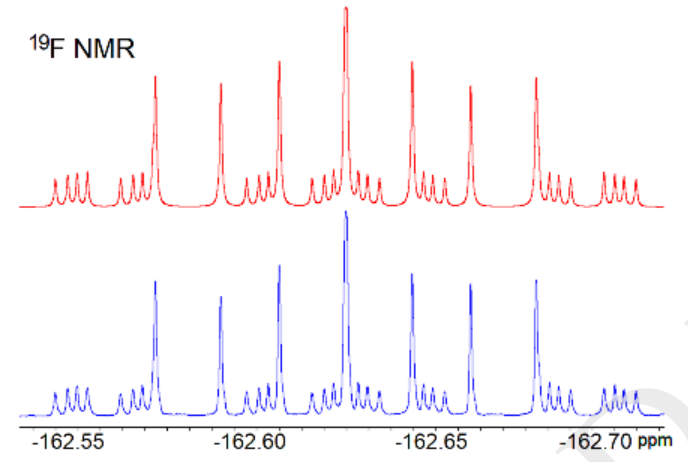

Highlights:

- A free and simple use NMR analysis program to extract coupling constants from complicated NMR multiplets.

- Applied to pentafluorobenzene ${ }^{1} \mathrm{H}$ and ${ }^{19} \mathrm{~F}$ spectra which yielded accurate analyses in just a few seconds.

- For the first time, used to analyse the ${ }^{19} \mathrm{~F}$ spectra, ${ }^{13} \mathrm{C}$ and ${ }^{19} \mathrm{~F}-{ }^{13} \mathrm{C}$-satellite spectra of tetrafluoro-4-(morpholino)pyridine

- The complicated ${ }^{13} \mathrm{C}$ and ${ }^{19} \mathrm{~F}-{ }^{13} \mathrm{C}$-satellite spectra were analysed within a few minutes.

- Excellent results are obtained even when the input date is inaccurate.

- Gaussian-03 derived coupling constants are a reasonable estimate to start analysis.

\section{Abstract}

A new and simple to use line-shape analysis method ANATOLIA (ANAlysis of TOtal LIneshApe) optimised all and ${ }^{19} \mathrm{~F}-{ }^{19} \mathrm{~F}$ and ${ }^{19} \mathrm{~F}-{ }^{1} \mathrm{H}$ coupling constants in pentafluorobenzene $\left(A A^{\prime} B B^{\prime} C^{\prime} H\right.$ ) within 10 seconds. This free and open-source NMR analysis method, which 
works within the Bruker Topspin-4 software and can import Bruker/JEOL/Varian data, was able to accommodate grossly inaccurate input coupling constants to provide an accurate result even for the second-order interactions ${ }^{4} \mathrm{~J}_{\mathrm{AA}^{\prime}}$ and ${ }^{4} \mathrm{~J}_{\mathrm{BB}^{\prime}}$. The ${ }^{13} \mathrm{C}$ spectrum and the ${ }^{19} \mathrm{~F}-$ ${ }^{13} \mathrm{C}$-satellites share the same coupling values, but required manual intervention to achieve an acceptable fit, especially for the ${ }^{19} \mathrm{~F}_{\mathrm{BB}^{\prime}}{ }^{13} \mathrm{C}$-satellites which are deceptively simple but have significant second-order effects and display $\Delta \delta{ }^{19} \mathrm{~F}_{\mathrm{B}}-{ }^{19} \mathrm{~F}_{\mathrm{B}^{\prime}}$ of $\sim 100 \mathrm{~Hz}$.

A real-world analysis of a new compound, that has potential anti-cancer drug activity, tetrafluoro-4-(morpholino)pyridine molecule, is shown for the first time. The ${ }^{19} \mathrm{~F}$ spectrum consists of a spin-system of 8 coupling nuclei $\left(A^{\prime} A^{\prime} B^{\prime}-H_{4}\right)$ which was analysed within 20 seconds. The ${ }^{13} \mathrm{C}$ satellites in the ${ }^{19} \mathrm{~F}$ spectrum consist of 9-spins $\left(\mathrm{AA}^{\prime} \mathrm{BB}^{\prime}-{ }^{13} \mathrm{C}-\mathrm{H}_{4}\right)$ and the carbon spectrum shows a series of ${ }^{13} \mathrm{C}$ isotopomer multiplets consisting of 5 coupling nuclei $\left({ }^{13} \mathrm{C}-A A^{\prime} B B^{\prime}\right)$ was optimised in less than a minute using a laptop computer.

$A b$ initio structure optimisations were carried out using B3LYP/6-31G*, and chemical shifts and coupling constants were calculated with the basis-set B3LYP/6-311 ${ }^{++} \mathrm{G}^{* *}$. Fluorine and carbon chemical shifts were in reasonable agreement with experimental values, and $\mathrm{nJ}_{\mathrm{FF}}$ and ${ }^{2-4} J_{C F}$ couplings were close to the experimental values, such that these were reasonable starting values for the ANATOLIA optimisation.

Keywords: ${ }^{19} \mathrm{~F}$ NMR spectroscopy, pentafluorobenzene, tetrafluoro-4-(morpholino)pyridine, spectral analysis, ANATOLIA.

\section{Introduction}

More than $20 \%$ of new pharmaceutically active drugs contain a fluorine atom [1 1], and there is renewed interest in understanding complex features that often appear in ${ }^{19} \mathrm{~F} \mathrm{NMR}$ spectra [3]. Extracting accurate chemical shift values and scalar coupling constants from liquid-state NMR spectra remains a significant challenge as the second-order effects have a substantial influence on the appearance of the spectrum, such that many couplings are not reported in the literature.

A fundamental understanding of ${ }^{19} \mathrm{~F}-{ }^{19} \mathrm{~F}$ and ${ }^{19} \mathrm{~F}-{ }^{13} \mathrm{C}$ couplings was obtained in the 1960 's onwards: including the influence of solvent and temperature [4], the complex interplay of size and sign of fluorine-fluorine and fluorine-carbon coupling constants for pyridine systems [5], fluoropyridines [6], carbocations [7] and fluorobenzene [8]. A detailed database of fluorine coupling constants was created by Emsley et al in 1976 [9], and specific interactions of ${ }^{2}{ }^{15} \mathrm{~N}-{ }^{19} \mathrm{~F}$ coupling in a fluoropyridine reported in 1979 [10], and a family of fluoropyridines in 1994 [11]. More recently fluorinated pharmaceuticals have renewed interest in fluorine NMR spectral analysis [12], and a book published in 2016 provides a detailed summary of ${ }^{19} \mathrm{~F}$ NMR methods and literature to date [13].

Recent interest in benchtop NMR spectrometers $[14,15]$ has led to a resurrection in spectral analysis at $40-80 \mathrm{MHz}$ in order to help understand the complex second-order effects that 
are more pronounced at low-field [16], for chemical research [17], hyperpolarisation methods [18], and educational purposes [19 20 21]. Modern methods and computational efficient calculations have vastly improved our chances of solving such NMR problems, and graphic-based calculations such as those featured in WinDNMR [22], NMR-SIM [23], and efficient code in SPINACH [24], as well as iterative methods such as SpinWorks [25] have been of great help to NMR specialists.

There are many useful experimental NMR methods that can extract detailed chemical shift and coupling constant data from spectra. The elegant TOCSY method (total correlation spectroscopy) highlighted by Parella [26] to selectively irradiate a ${ }^{1} \mathrm{H}-{ }^{13} \mathrm{C}$ satellite peak in order to obtain small ${ }^{2} \mathrm{~J}_{\mathrm{HC}}$ and ${ }^{3} \mathrm{~J}_{\mathrm{HC}}$ hetero-couplings that are hidden by the ${ }^{1} \mathrm{H}-{ }^{12} \mathrm{C}$ signals was investigated, however, achieving sufficient signal-to-noise was challenging for the real-world tetrafluoro(morpholino)pyridine sample. Also, sel-EXCIDE [27] (excitation-sculptured indirect-detection experiment, a selective variant of the HSQC method to measure ${ }^{n} \mathrm{~J}_{\mathrm{CH}}$ coupling constants) and Het-Loc [28] (a 2D TOCSY to extract size and sign of ${ }^{1} \mathrm{~J}_{\mathrm{HC}},{ }^{2} \mathrm{~J}_{\mathrm{HC}}$ and ${ }^{3} \mathrm{~J}_{\mathrm{HC}}$ coupling constants) methods work well for many molecules but less well for these complex second-order spectra, and g-DQ-COSY (gradient-enhanced double quantum correlation spectroscopy) and e-COSY [29] (exclusive-correlation spectroscopy, a filtered COSY that only displays the active couplings) work well but it is difficult to obtain sufficient resolution in the $f_{1}$ dimension for the large spectral widths in these ${ }^{19} \mathrm{~F}$ spectra. These methods can in principle provide the relative size and sign assignment of ${ }^{n} \mathrm{~J}_{\mathrm{C}-\mathrm{F}}$ couplings, however, are limited in this example as complexity of the spin-system and achievable resolution in the second dimension for ${ }^{19} \mathrm{~F}$ spectra over $100 \mathrm{ppm}$ range prevent acceptable results from being obtained in an acceptable time-frame. Elegant triple-resonance 2D HSQC and $\mathrm{HMBC}$ experiments [30] and F-C HSQC, J-scaled F-C HMBC, F2-selective F-C XLOC, F2selective $\mathrm{F}-\mathrm{C} H M Q C$, and $\mathrm{F}-\mathrm{F}$ COSY [31] have not been attempted at this time. Also, classic homo-nuclear decoupling of the ${ }^{19} \mathrm{~F}$ multiplets provided limited improvement in multiplet complexity as decoupling AA' still left a complex multiplet for BB'. The J-RES [32] (2D Jresolved experiment, to separate the chemical shift from the coupling multiplet to reduce multiplet overlap and yield a pseudo-singlet for each multiplet), Pure-Shift [33] and PSYCHE [34] methods were of interest to visualise the pseudo singlets, particularly for the ${ }^{19} \mathrm{~F} \Delta \delta$ in the ${ }^{19} \mathrm{~F}-{ }^{13} \mathrm{C}$-satellite signals, however, the complex second-order effects and $\mathrm{S} / \mathrm{N}$ issues prevented suitably useful spectra from being obtained. Thus, just the simple $1 \mathrm{D}^{19} \mathrm{~F},{ }^{13} \mathrm{C}$ and ${ }^{13} \mathrm{C}\left\{{ }^{1} \mathrm{H}\right\}$ spectra that are available to all synthetic chemists were used in this study.

In 2018 a new line-shape algorithm approach ANATOLIA (ANAlysis of TOtal LIneshApe) [35] was made available as open-source free software, that applies a series of line broadening effects ( $L B=4.0,3.0,2.0,1.0,0.8,0.6,0.4,0.2$,) to both the experimental and calculated spectra before parameters are optimised. This has the effect of avoiding thousands of local minima that provide good fits but are based on inaccurate parameters, and thus enables a wider landscape of parameter values to be explored and this increases the probability of locating the global minimum.

The authors of the ANATOLIA program have successfully analysed closely coupled ${ }^{1} \mathrm{H}-{ }^{1} \mathrm{H}$ multiplets in ortho-dichlorobenzene $\left(A A^{\prime} B B^{\prime}\right)$ and styrene ( $\left.A A^{\prime} B B^{\prime} C D E F\right)$. In our lab the ${ }^{1} H$ 
aromatic and alkene resonances in cis- and trans-stilbene [19], ${ }^{19} \mathrm{~F}-{ }^{19} \mathrm{~F}$ multiplets in perfluorotoluene ( $\left.A A^{\prime} B B^{\prime} C^{\prime} D D D\right)$ and complex multiplets in 1-perfluorotol-4-yl-2perfluorotol-4-yl-oxymethyl-1H-benzimidazole ${ }^{19} \mathrm{~F}-{ }^{1} \mathrm{H}$ 9-spin-system ( $\mathrm{AA}^{\prime} \mathrm{BB}^{\prime} \mathrm{CCCYY}$ ) and 10 spin-system (XX'YY'ZZZBBH) [36] have been analysed. Of particular note is that these multiplets display significant second-order effects, where $\Delta \delta{ }^{19} \mathrm{~F}$ was non-zero, and the scalar couplings were up to $\pm 7 \mathrm{~Hz}$. Therefore, the appearance of these multiplets was very sensitive to the size and sign of these couplings, which made traditional assign-iterate methods challenging, as the input data tends to need to be very accurate before refinement can be successful.

Here, ANATOLIA was applied to the complex ${ }^{19} \mathrm{~F}$ and ${ }^{13} \mathrm{C}$ spin-systems of the wellcharacterised compound pentafluorobenzene and a novel tetrafluoro-4(morpholino)pyridine compound.

\section{Results and discussion}

Accurate analysis of the ${ }^{1} \mathrm{H}$ and ${ }^{19} \mathrm{~F}$ NMR data from pentafluorobenzene was achieved in 1965 [37] when uncertainty regarding the sign of coupling constants was still being discussed, and most recently investigated in a liquid crystal solvent in 2011 [38] where the sign of scalar coupling is implicit in the analysis of the dipolar couplings [39 40]. The ability to accurately calculate ${ }^{4} \mathrm{~J}_{\mathrm{FF}}$ and ${ }^{5} \mathrm{~J}_{\mathrm{FF}}$ coupling constants remains a challenge for most $a b$-initio methods, but the latest semi-empirical method of Abraham [41] offers a rapid and accurate way to estimate these second-order couplings. To test the robustness of the ANATOLIA program, a grossly inaccurate "Parameters_start" file was created, with ${ }^{4} \mathrm{~J} A A^{\prime}=0.0 \mathrm{~Hz}$ and ${ }^{4} \mathrm{~J} \mathrm{BB}^{\prime}=0.0 \mathrm{~Hz}$ as these are not obvious from the NMR spectrum nor the literature for a nonspecialist, ${ }^{3} \mathrm{~J}_{\mathrm{FF}}$ was set at $-20.0 \mathrm{~Hz}$ which is a value that can be read directly from the multiplet " $C$ " of the para-fluorine or obtained from the ${ }^{19} \mathrm{~F}$ coupling constant almanac [9], all other couplings were set to $9.0 \mathrm{~Hz}$. These are perhaps reasonable values that a novice bench chemist may estimate as a starting point. All fluorine chemical shifts were selected for optimisation $A A^{\prime} B B^{\prime}$ and $C\left(1,2,3\right.$ "Input_Data" file) and all coupling constants $A A^{\prime}, A B, A B^{\prime}$, $A C, A H, A^{\prime} B, A^{\prime} B^{\prime}, A^{\prime} C, A^{\prime} H, B B^{\prime}, B^{\prime} C, B^{\prime} H$ and $C H(5,6,7,8,9,10,11,12,13$ in the "Input_Data" file) and finally the parameter "LW" which optimises the linewidth. ANATOLIA optimised all parameters and produced an excellent fit within 10 seconds. The closeness of the fit (Figure 1 ) is very encouraging for all the $A A^{\prime}, B B^{\prime}, C$ and $H$ multiplets, and this is confirmed by the accuracy of the data (Table 1).

\subsection{Pentafluorobenzene: Analysis of the ${ }^{19} \mathrm{~F}$ and ${ }^{1} \mathrm{H}$ spectra.}

Subtleties such as the relative sign of each coupling constant are perhaps beyond the experience of most bench chemists, but the specialist literature [17] shows that ${ }^{3} \mathrm{~J}_{\mathrm{FF}}$ is usually negative, and most ${ }^{4} J_{F F}$ and ${ }^{5} J_{F F}$ are positive. Therefore, this ANATOLIA result is extremely accurate not just on magnitude but also on sign.

The ANATOLIA method allows individual or small sets of parameters to be selected for optimisation such that " 123 " will select the AA' BB' and C chemical shifts to be free to improve. These improved values can be inserted back into the "Input_Data" file, and a new set of parameters selected, “5 6789101112 13" will optimise all coupling constants, and 
finally, "14" will optimise the linewidth. The spin labels for each atom are provided in figure 2 , and labels for optimisation parameters in the experimental section.
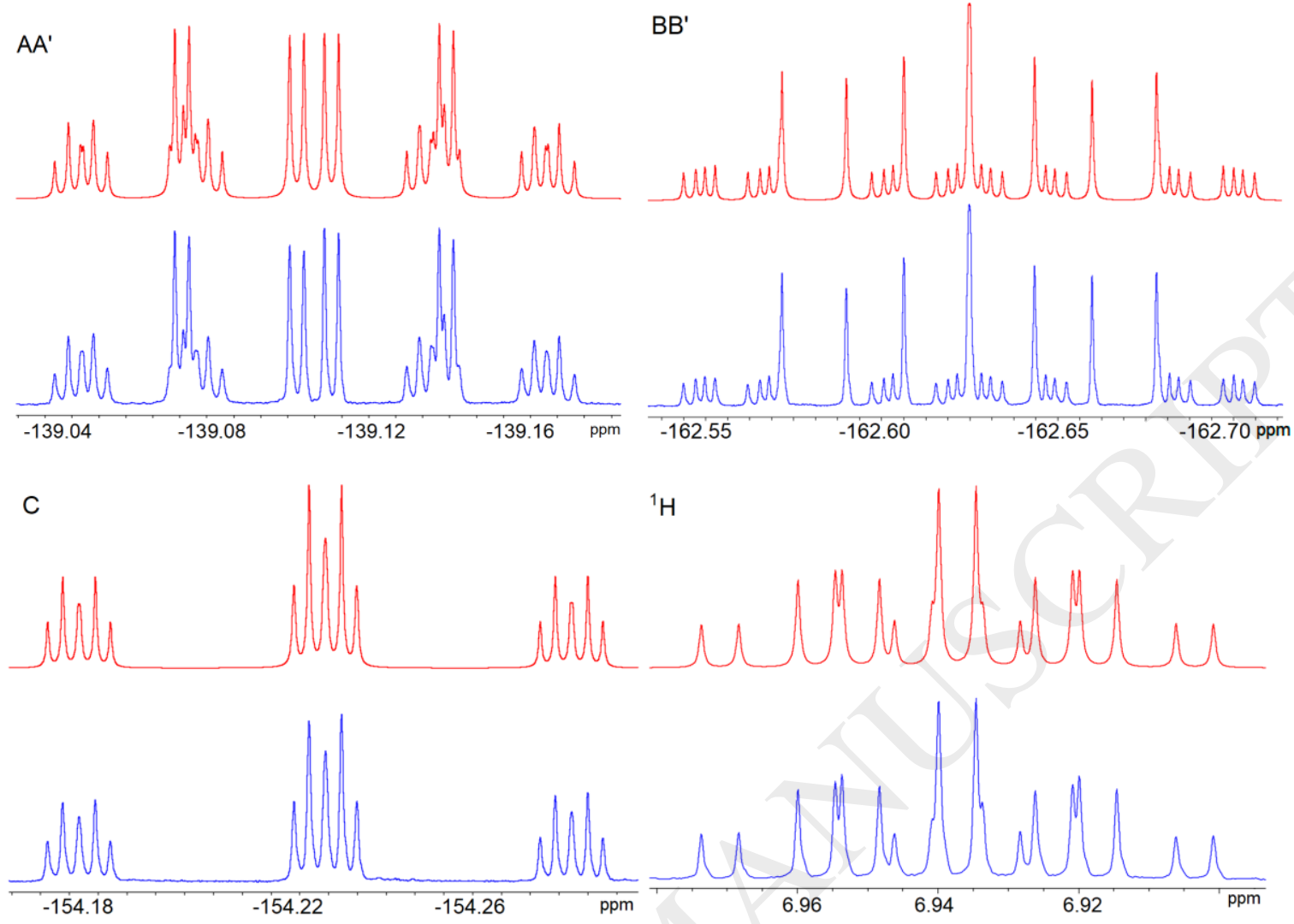

Figure 1. Experimental(lower) and simulated(upper) ${ }^{19} \mathrm{~F}$ and ${ }^{1} \mathrm{H}$ NMR spectra of pentafluorobenzene (recorded in $\mathrm{CDCl}_{3}$ using a Bruker-Avance-I 500 NMR spectrometer, referenced to $\mathrm{CFCl}_{3}$ and TMS respctively). $\mathrm{AA}^{\prime}=$ ortho-, $\mathrm{BB}^{\prime}=$ meta-, $\mathrm{C}=$ para-fluorine atoms.

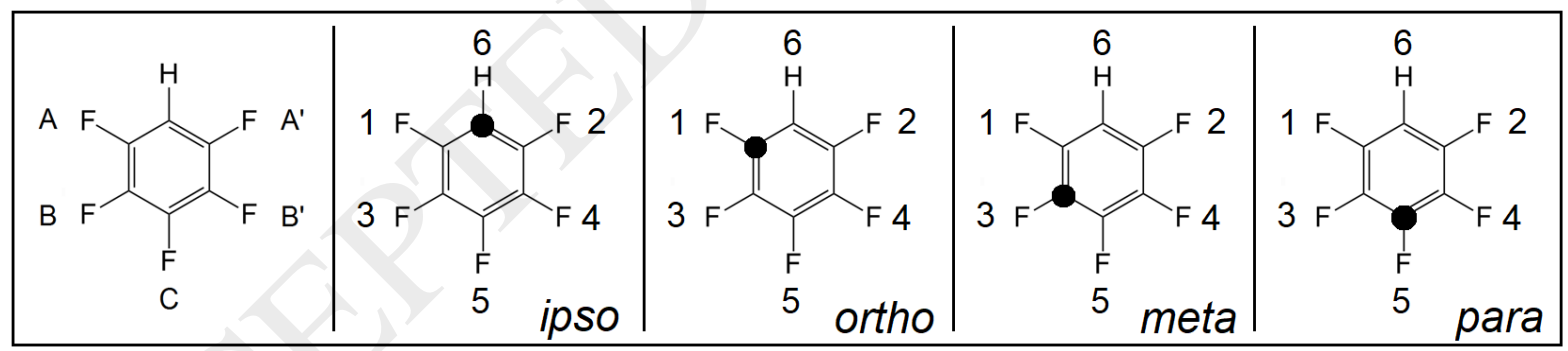

Figure 2. Structure of pentafluorobenzene with spin-system labels $\left(A A^{\prime} B B^{\prime} C H\right)$ and number labels(ANATOLIA) for isotopomers responsible for the ${ }^{13} \mathrm{C}$ and ${ }^{19} \mathrm{~F}-{ }^{13} \mathrm{C}$-satellites.

\begin{tabular}{|l|l|l|l|l|l|l|l|}
\hline & & $1965^{\mathrm{a}}$ & $2011 \mathrm{LC}^{\mathrm{b}}$ & SpinWorks $^{\mathrm{C}}$ & ANATOLIA $^{\mathrm{d}}$ & ANATOLIA $^{\mathrm{e}}$ & $\mathrm{G}^{-03^{\mathrm{f}}}$ \\
\hline $\begin{array}{l}1, \\
2\end{array}$ & 4J $\mathrm{AA}^{\prime}$ & \pm 2.4 & -1.748 & -2.188 & -2.173 & -2.13 & 5.86 \\
\hline $\begin{array}{l}1, \\
3\end{array}$ & 3J AB & \pm 20.6 & -21.224 & -21.782 & -21.781 & -21.46 & -21.39 \\
\hline $\begin{array}{l}1, \\
4\end{array}$ & 5J $\mathrm{AB}^{\prime}$ & \pm 8.8 & 8.667 & 8.700 & 8.738 & 8.74 & 10.73 \\
\hline $\begin{array}{l}1, \\
5\end{array}$ & 4J AC & \pm 1.3 & 1.141 & 1.240 & 1.235 & 1.24 & -1.50 \\
\hline
\end{tabular}




\begin{tabular}{|l|l|l|l|l|l|l|l|}
\hline $\begin{array}{l}1, \\
6\end{array}$ & 3J $\mathrm{AH}$ & \pm 10.2 & 10.688 & 10.00 & 10.02 & 10.09 & 7.14 \\
\hline $\begin{array}{l}3, \\
4\end{array}$ & 4J $\mathrm{BB}^{\prime}$ & \pm 1.2 & -1.235 & -1.219 & -1.195 & -1.15 & -4.23 \\
\hline $\begin{array}{l}3, \\
5\end{array}$ & 35 BC & \pm 18.8 & -19.381 & -20.110 & -20.110 & -19.74 & -21.14 \\
\hline $\begin{array}{l}3, \\
6\end{array}$ & 4J BH & \pm 6.9 & 7.147 & 6.9 & 6.873 & 6.87 & 5.28 \\
\hline $\begin{array}{l}5, \\
6\end{array}$ & 5J $\mathrm{CH}$ & \pm 2.7 & -2.636 & -2.657 & -2.659 & -2.67 & -2.44 \\
\hline
\end{tabular}

Table 1. ${ }^{19} \mathrm{~F}$ coupling constants from spectral analysis of pentafluorobenzene. a) ref. [37], b) ref. [38] dissolved in a liquid-crystal, c) this work analysed using SpinWorks and data acquired using a 500 $\mathrm{MHz}$ magnet, d) this work analysed using ANATOLIA and data acquired using a $400 \mathrm{MHz}$ magnet, e) this work analysed using ANATOLIA and data acquired using a $500 \mathrm{MHz}$ magnet, f) calculated coupling constants using Gaussian-03 nmr=spin-spin B3LYP/6-311 ${ }^{++} \mathrm{G}^{* *}$.

One significant advantage of the ANATOLIA method over some traditional assign-iterate methods is the fact that the input coupling constants can be inaccurate and produce a spectrum that does not resemble the experimental spectrum, yet the optimisation process improved these values and produced useful data. In addition, the facility to define and control symmetry using the numerical labelling system in "Input_Data" file is a very useful feature in terms of constraining the analysis to meaningful values and speeding up the analysis. Hence ${ }^{3} \mathrm{~J} A B$ is linked to ${ }^{3} \mathrm{~J}^{\prime} \mathrm{B}^{\prime}$ as a single variable and ${ }^{5} \mathrm{~J} A \mathrm{~B}^{\prime}$ and ${ }^{5} \mathrm{~J} \mathrm{~A}^{\prime} \mathrm{B}$ are linked as a single variable. A detailed investigation of chemical shifts and coupling constants from Gaussian-03 calculations [42] was not the main focus of this work, never the less, it is of interest to determine if calculated values obtained using a "reasonable" method and basis set can be used as a starting point. Thus, the Gaussian-03 derived values in Table 1 were used as input for analysis of the ${ }^{19} \mathrm{~F}$ multiplets, the optimisation was complete within 10 seconds and provided very similar data. The fit obtained was excellent, despite the input size and sign of ${ }^{4} \mathrm{~J} A \mathrm{~A}^{\prime}$ being very different $(+5.86 \mathrm{~Hz}$ vs $-2.17 \mathrm{~Hz})$, however, the sign of the ${ }^{4} \mathrm{~J}$ $A C{ }^{19} \mathrm{~F}-{ }^{19} \mathrm{~F}$ coupling was incorrect $(-1.50 v s+1.24)$, which highlights the need for diligence. Starting with the correct sign of this coupling provided identical values as for a "best guess" set of input parameters.

Several spin-systems have been analysed to date, and as the definition files are reusable and recyclable for other similar spectra, it is useful to know that several other spectra have been successfully and quickly analysed: a 4-spin-system (ABCD) aromatic ${ }^{1} \mathrm{H}$ spectrum, 6-spinsystem (ABCD-YY'), a ${ }^{19} \mathrm{~F}^{19} \mathrm{~F}^{8}$-spin-system (AABBCDDD) of perfluorotoluene, a ${ }^{19} \mathrm{~F}-{ }^{1} \mathrm{H}$ 9-spinsystem (XXYYZZZBB), and a ${ }^{19} \mathrm{~F}-{ }^{1} \mathrm{H}$ 9-spin-system (AABBCCCYYH) with analysis time ranging from a few seconds for the simple symmetric spin-systems to a maximum analysis time of 7 minutes for the most complex asymmetric spin-systems [43].

\subsection{Pentafluorobenzene: ${ }^{13} \mathrm{C}$ Isotopomers and the ${ }^{13} \mathrm{C}$-spectrum.}


The traditional ${ }^{13} \mathrm{C}\left\{{ }^{1} \mathrm{H}\right\}$ carbon spectrum shows the large 'doublets' formed for the ${ }^{13} \mathrm{C}-{ }^{19} \mathrm{~F}$ groups, and some finer detail from the smaller ${ }^{n} \mathrm{~J}_{\mathrm{CF}}$ couplings. In order to obtain a welldigitised spectrum that displays all details of these complex multiplets, the ${ }^{13} \mathrm{C}$ spectrum was recorded without ${ }^{1} \mathrm{H}$ decoupling to allow a long acquisition time of 6.5 seconds to be used. The ${ }^{1} \mathrm{H}$-coupled spin-system ${ }^{13} \mathrm{C}-\mathrm{AA}^{\prime} \mathrm{BB}^{\prime} \mathrm{CH}$ that exists for the each of the 4 carbon-13 isotopomers (ipso, ortho, meta and para ${ }^{13} \mathrm{C}$ positions) creates four new sub-spectra to analyse in the ${ }^{13} \mathrm{C}$ spectrum (Figure 3 ). These multiplets are deceptively simple and usually require considerable time to analyse in detail using traditional assign-iterate methods, indeed, the complex interplay between ${ }^{19} \mathrm{~F}-{ }^{19} \mathrm{~F}$ couplings and ${ }^{1} \mathrm{~J}-{ }^{4} \mathrm{~J} C \mathrm{C}$ couplings means that exact solutions are rarely reported. However, ANATOLIA was able to yield accurate fits and extract accurate data for all ${ }^{13} \mathrm{C}$ isotopomer multiplets by employing a pragmatic series of manual interventions to optimise parameters in a stepwise manner. Then these data were used to fit the ${ }^{19} \mathrm{~F}-{ }^{13} \mathrm{C}$-satellite signals, with no modification required to achieve a good fit, as the data comprise of the same spin-system $\left({ }^{13} \mathrm{C}-\mathrm{A} \mathrm{A}^{\prime} \mathrm{BB} \mathrm{B}^{\prime} \mathrm{CH}\right)$. The manual intervention simply involves reducing the number of parameters that are allowed to be optimised, here the known parameters such as ${ }^{19} \mathrm{~F} \delta \Delta$ for $A A^{\prime}$ and $B^{\prime}$ ' which were determined earlier, are locked while ${ }^{n} \mathrm{~J}_{C H}$ values which are unknown were set to be free and were allowed to be optimised. Values such as the chemical shift of the carbon, that can be accurately measured from the experimental spectrum and do not need to be optimised at this stage, are also locked. In this way the optimisation has just a few parameters, which has a two-fold advantage, firstly the optimisation progresses rapidly with fewer parameters and secondly, only the most important parameters are optimised.

The $\mathrm{C}_{2}$ symmetry of the ipso and para ${ }^{13} \mathrm{C}$ isotopomers is clear in the first-order nature of the ${ }^{13} \mathrm{C}$ multiplets, with ${ }^{19} \mathrm{~F}$ chemical shifts $\mathrm{A}=\mathrm{A}^{\prime}$ and $\mathrm{B}=\mathrm{B}^{\prime}$, and couplings $\mathrm{C}-\mathrm{A}=\mathrm{C}-\mathrm{A}^{\prime}$ and $\mathrm{C}-\mathrm{B}$ $=\mathrm{C}-\mathrm{B}^{\prime}$, forming a classic d-t-d-t (ipso) and d-t-t-d (para) multiplet patterns. The symmetry is broken for the isotopomers with a ${ }^{13} \mathrm{C}$ in the ortho or meta positions, here all the ${ }^{1} \mathrm{~J}-{ }^{4} \mathrm{~J} \mathrm{C}-\mathrm{F}$ couplings are different to each other, and ${ }^{19} \mathrm{~F} \Delta \delta$ for $A A^{\prime}$ and $\mathrm{BB}^{\prime}$ can be non-zero. This effect is noticeable for the meta $\left(A A^{\prime}\right){ }^{13} \mathrm{C}$ multiplets at $137 \mathrm{ppm}$ and the matching ${ }^{19} \mathrm{~F}-{ }^{13} \mathrm{C}$-satellite multiplets, which are particularly asymmetric as $\Delta \delta$ for $\mathrm{AA}^{\prime}$ and $\mathrm{BB}^{\prime}$ are each $\sim 100 \mathrm{~Hz}$ (Table 2). The calculated ${ }^{1} \mathrm{~J}_{\mathrm{CH}}$ coupling constants, using density functional theory gaugeindependent atomic orbital method employing B3LYP/6-311++G**, were always much larger ( $\sim 30 \%)$ than the experimental values and therefore of little use as a starting value for optimisation. Luckily, these coupling constants can be measured accurately and directly from the experimental spectra, but recent methods have been published to accurately calculate ${ }^{1} \mathrm{~J}_{\mathrm{CH}}$ coupling constants. [44] The ${ }^{2} \mathrm{~J}_{\mathrm{CH}},{ }^{3} \mathrm{~J}_{\mathrm{CH}}$ and $4 \mathrm{~J}_{\mathrm{CH}}$ coupling constants are traditionally difficult to extract from the experimental NMR spectrum via analysis, here the Gaussian-03 calculations shows that these coupling constants are reasonably close to the experimental values and thus can be used as a starting point for ANATOLIA optimisation. The influence of the basis set on the calculated chemical shifts and coupling constants is known to be significant [45] across the range B3-LYP/6-31G, 6-31G*, 6-31G**, 6-31+G*, 6$31+G * *, 6-31++G * *, 6-311+G *, 6-311+G * *, 6-311++G * *$ for the Gaussian-03 keyword "nmr=spinspin", with the most accurate data being produced using the $6-311++\mathrm{G}^{* *}$ basis set. Much more consistent results were obtained across the same range of basis sets using 
Gaussian-09 where the keyword "nmr=mixed" was available, thus B3-LYP/6-31G* (Gaussian$09 \mathrm{nmr}=$ mixed) produced data very similar to the more time consuming B3-LYP/6311++G**(Gaussian-03 nmr=spinspin).

\subsection{Pentafluorobenzene: ${ }^{13} \mathrm{C}$ Isotopomers and the ${ }^{19} \mathrm{~F}-{ }^{13} \mathrm{C}$-satellites.}

The ${ }^{13} \mathrm{C}$ "satellites" are a common feature of the ${ }^{1} \mathrm{H}$ NMR spectra and are often ignored, even though they are responsible for HMQC, HSQC and HMBC 2D spectra methods. Here, the ${ }^{19} \mathrm{~F}-{ }^{13} \mathrm{C}$ satellites (Figure 4 ) are clearly visible at $\sim 0.5 \%$ intensity in the spectrum either side of the large ( $99 \%$ intensity) parent ${ }^{19} \mathrm{~F}-{ }^{12} \mathrm{C}$ multiplet, the ${ }^{1} \mathrm{~J} \mathrm{C}-\mathrm{F}$ coupling is approximately $-250 \mathrm{~Hz}$ (negative coupling) and the satellite "doublet" is shielded by the ${ }^{13} \mathrm{C}$ isotope effect to smaller chemicals shift thus is not positioned symmetrically about the parent multiplet. Thus, the right-hand side of the satellite is generally more clearly visible than the left-hand side and there is often considerable overlap and baseline distortion, this is a challenge for a line-shape fitting method. The optimised data from the ${ }^{19} \mathrm{~F}$ and ${ }^{13} \mathrm{C}$ spectral analysis were used as input and ANATOLIA was able to optimise the coupling constants and $\Delta \delta{ }^{19} \mathrm{~F}$ shifts to provide an excellent fit and accurate data, confirming the validity of the previous analyses.

\begin{tabular}{|c|c|c|c|c|c|c|c|}
\hline & ANATOLIA & G-03 & & & ANATOLIA & G-03 & \\
\hline & \multicolumn{2}{|l|}{ Ortho } & \multirow{7}{*}{ c ortho } & & \multicolumn{2}{|l|}{ Meta } & \multirow{7}{*}{ C } \\
\hline$A-A$ & -248.72 & -318.16 & & B-A & 10.09 & 9.93 & \\
\hline$A-A^{\prime}$ & 7.38 & 6.42 & & $B-A^{\prime}$ & 16.41 & 5.99 & \\
\hline$A-B$ & 11.16 & 5.15 & & B-B & -250.63 & -319.33 & \\
\hline$A-B^{\prime}$ & -4.25 & 5.08 & & $B-B^{\prime}$ & -1.42 & -2.15 & \\
\hline$A-C$ & -3.76 & 0.006 & & B-C & 9.14 & 6.56 & \\
\hline \multirow[t]{2}{*}{$\mathrm{A}-\mathrm{H}$} & 12.15 & 6.47 & & $\mathrm{~B}-\mathrm{H}$ & 12.83 & 8.26 & \\
\hline & \multicolumn{2}{|l|}{ Para } & & & \multicolumn{2}{|l|}{ Ipso } & \\
\hline$C-A$ & 5.22 & 1.44 & & C-A & 23.03 & 14.16 & $\mathrm{H}$ \\
\hline$C-A^{\prime}$ & 5.22 & 1.44 & & $C-A^{\prime}$ & 23.03 & 14.16 & \\
\hline C-B & 13.31 & 6.84 & & C-B & 0.42 & -2.87 & \\
\hline$C-B^{\prime}$ & 13.31 & 6.84 & & C-B' & 0.42 & -2.87 & B \\
\hline$C-C$ & -253.91 & -321.89 & $\dot{F}$ & $\mathrm{C}-\mathrm{C}$ & -3.60 & 3.88 & $\mathrm{~F}$ \\
\hline $\mathrm{C}-\mathrm{H}$ & -1.72 & -1.52 & c para & $\mathrm{C}-\mathrm{H}$ & 169.98 & 160.43 & ipso \\
\hline
\end{tabular}

Table 2. Pentafluorobenzene coupling constants $(\mathrm{Hz})$ obtained by analysis of the multiplets in the ${ }^{13} \mathrm{C}$ spectrum for each isotopomer (ANATOLIA) and the calculated coupling values from Gaussian-03 B3LYP/6-311++G** nmr=spinspin, symmetric for ipso- and para-, asymmetric for ortho- and meta-. The chemical shifts ${ }^{19} \mathrm{~F}_{\mathrm{A}}={ }^{19} \mathrm{~F}_{\mathrm{A}^{\prime}}$ and ${ }^{19} \mathrm{~F}_{\mathrm{B}}={ }^{19} \mathrm{~F}_{\mathrm{B}^{\prime}}$ are equal for ortho-, but $\Delta \delta{ }^{19} \mathrm{~F}$ for meta- is $\sim 100 \mathrm{~Hz}$ for each, ${ }^{19} \mathrm{~F}_{\mathrm{A}} \neq{ }^{19} \mathrm{~F}_{\mathrm{A}^{\prime}}$ and ${ }^{19} \mathrm{~F}_{\mathrm{B}} \neq{ }^{19} \mathrm{~F}_{\mathrm{B}^{\prime}}$. 

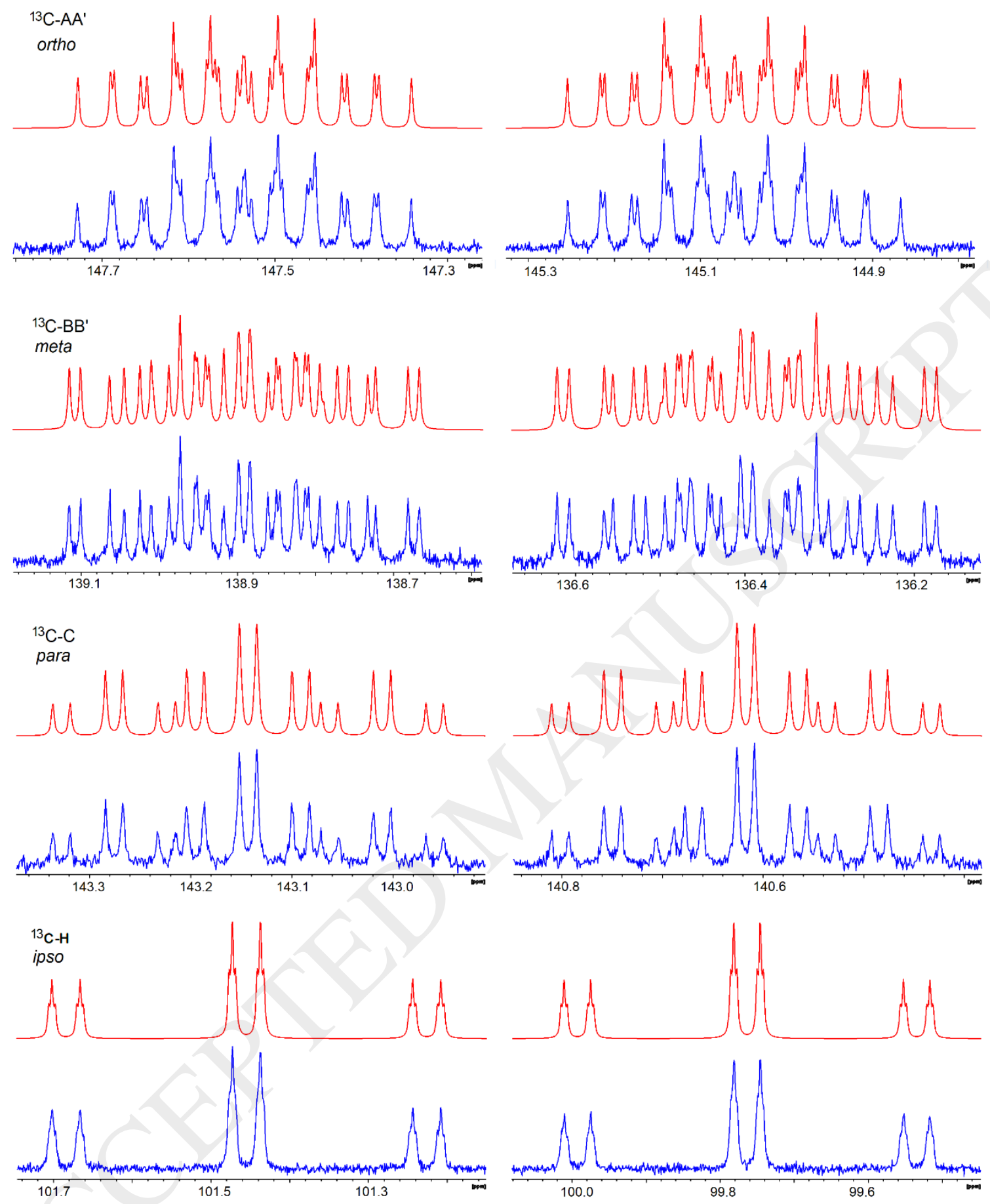

Figure 3. Pentafluorobenzene ${ }^{13} \mathrm{C}$ NMR spectrum (recorded using a $400 \mathrm{MHz}$ magnet, without ${ }^{1} \mathrm{H}$ decoupling) showing expansions of the "doublets" and detailed multiplets therein for ipso- ${ }^{13} \mathrm{C}-\mathrm{H}$, ortho- ${ }^{13} \mathrm{C}-\mathrm{AA}^{\prime}$, meta- ${ }^{13} \mathrm{C}-\mathrm{BB}^{\prime}$, and para $-{ }^{13} \mathrm{C}-\mathrm{C}$ carbons (experimental lower and ANATOLIA optimised - upper). 

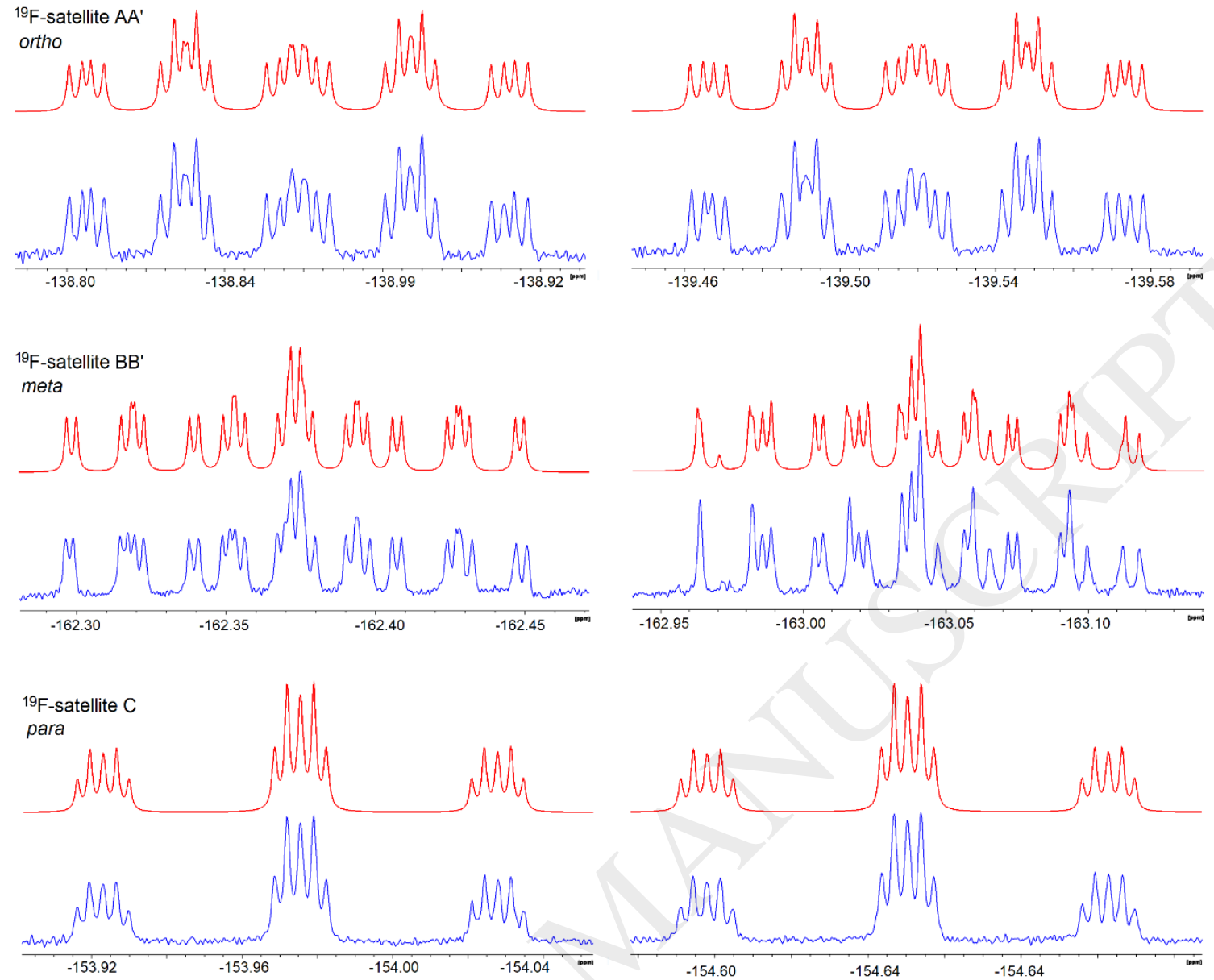

Figure 4. Pentafluorobenzene ${ }^{19} \mathrm{~F}$ NMR spectrum showing expansions of the ${ }^{19} \mathrm{~F}-{ }^{13} \mathrm{C}$-satellites for ortho $\left(\mathrm{AA}^{\prime}\right)$, meta $\left(\mathrm{BB}^{\prime}\right)$ and para $(\mathrm{C})$ fluorine atoms (experimental - lower and ANATOLIA optimised upper).

\subsection{Tetrafluoro-4-(morpholino)pyridine: Analysis of the ${ }^{19} \mathrm{~F}$ spectrum.}<smiles>[R]CN(CC)c1c(Br)c([Y17])nc(F)c1Br</smiles>

AA'BB'- $\mathrm{H}_{4}$<smiles>[2H]CN(C[2H])c1c(F)c(F)n[13c](F)c1F</smiles>

ortho- ${ }^{13} \mathrm{C}$ AA'BB'- $\mathrm{H}_{4}$<smiles>[2H]CN(C[2H])c1c(F)c(F)n[14c](F)[14c]1F</smiles><smiles>Fc1nc(F)c(F)c(N2CCOCC2)c1F</smiles>

meta- ${ }^{13} \mathrm{C}$ AA'BB'- $\mathrm{H}_{4}$

Figure 5. Tetrafluoro-4-(morpholino)pyridine: Chemical structures, spin-labels, ortho- and meta- ${ }^{13} \mathrm{C}-$ isotopomers. 
Here, strongly second-order coupling effects were observed in the ${ }^{19} \mathrm{~F}$ and ${ }^{13} \mathrm{C}$ NMR spectra of a tetrafluoro-4-(morpholino)pyridine compound. The ${ }^{19} \mathrm{~F}$ ortho- $A \mathrm{~A}^{\prime}$ atoms form a multiplet that can be defined as 4-spin-system ( $\left.A A^{\prime} B^{\prime}\right)$ and can be readily analysed, while the meta-BB' atoms form a more complex 8-spin-system $\left(\mathrm{AA}^{\prime} \mathrm{BB}^{\prime}-\mathrm{H}_{4}\right)$ that has several longrange $\mathrm{F}-\mathrm{H}$ couplings, that is slightly more difficult to analyse. In the ${ }^{13} \mathrm{C}$ spectrum, the presence of a single ${ }^{13} \mathrm{C}$ isotope in the aromatic ring (Figure 5) modifies the symmetry and introduces a series of additional ${ }^{1} \mathrm{~J}-{ }^{4} \mathrm{~J} C-F$ couplings into the spin-system, which make analysis much more challenging for the carbon spectrum and the ${ }^{19} \mathrm{~F}-{ }^{13} \mathrm{C}$-satellites. Thus, the $A A^{\prime} B B^{\prime}{ }^{19} \mathrm{~F}$ spectrum becomes a $X A A^{\prime} B B^{\prime}$ spin-system in the carbon spectrum, where the chemical shift of the fluorine atoms can be different and ${ }^{19} \mathrm{~F} \Delta \delta$ for $A A^{\prime} / \mathrm{BB}^{\prime}$ can be in the range of $0-27 \mathrm{~Hz}$. Also, coupling values no longer need to adhere to a higher symmetry, therefore $A B \neq A^{\prime} B^{\prime}$ and $A B^{\prime} \neq A^{\prime} B$ is possible. Furthermore, as the ${ }^{1} J_{C F}$ coupling is typically in the order of approximately $-250 \mathrm{~Hz}$ and $\Delta \delta{ }^{19} \mathrm{~F}$ is small $(0-27 \mathrm{~Hz})$, these ${ }^{13} \mathrm{C}$ multiplets are very sensitive to subtle changes in chemical shift and coupling constant, making this type of NMR spectrum a considerable challenge for both the traditional assign-iterate analyses and ANATOLIA. Finally, the ${ }^{13} \mathrm{C}$-satellite "doublets" in the ${ }^{19} \mathrm{~F}$ spectrum were analysed for ortho$A A^{\prime}$ and meta-BB', these multiplets are deceptively simple but contain significant complexity and as such serve as a significant challenge to the ANATOLIA program, not only in relation to the complex spin-system but also as these multiplets are partially obscured, of low signal-tonoise and distorted.

Traditional assign-iterate methods are robust and very well tested methods of extracting chemical shift and coupling data from complex spectra, however, these methods can require a significant input of time to elucidate a suitable set of accurate parameters, as often the parameters need to be close to the actual accurate values and manually modified which necessitates multiple iterative cycles.

It is reassuring that the ${ }^{19} \mathrm{~F} A A^{\prime} B B^{\prime}$ and $A A^{\prime} B B^{\prime} \mathrm{H}_{4}$ spin-systems were relatively simple to solve using ANATOLIA (Figure 6), with symmetry linked $\delta A=\delta A^{\prime}$ and $\delta B=\delta B^{\prime}$, and the ${ }^{3} J_{F F}$ coupling constant $A B=A^{\prime} B^{\prime}$ are similar to expected values of approximately $-21 \mathrm{~Hz}$. The $A A^{\prime}$ fluorine atoms ortho to the pyridine nitrogen display a complex multiplet, defined by the secondorder coupling ${ }^{4} \mathrm{AA}^{\prime}=-14.51 \mathrm{~Hz}$, whilst the $\mathrm{BB}^{\prime}$ fluorine atoms meta to the pyridine nitrogen show a more complex multiplet defined by the ${ }^{4} \mathrm{~J} \mathrm{BB}^{\prime}$ coupling of $-4.99 \mathrm{~Hz}$. The additional detail in the $\mathrm{BB}^{\prime}$ multiplet is due to a long-range coupling to four distant hydrogen atoms. Manual intervention (trial and error) was required to significantly increase the $A B^{\prime} / A^{\prime} B$ coupling to a value of $20 \mathrm{~Hz}$ (significantly larger that the $\sim 8 \mathrm{~Hz}$ for the fluorobenzene compounds), after which the calculated and experimental spectra showed an excellent fit that was obtained in 10 seconds for the $\underline{A A^{\prime}} B B^{\prime}$.

Optimisation resulted in an excellent fit for $A A^{\prime}$, however for BB' the fit was not exact enough to be acceptable. Manual intervention was required to hold the long range $5 \mathrm{~J} \mathrm{F-H}$ couplings to a fixed value of $1.5 \mathrm{~Hz}$. The manual intervention helped to prevent the optimisation from progressing to a false local minimum and enabled a much better solution to be identified which turned out to be the global minimum and produced an excellent fit for BB' multiplets. The ${ }^{19} \mathrm{~F}$ NMR spectrum had previously been analysed using assign-iterate 
method of NUMMRIT [46] in SpinWorks [47] which optimised to very similar results, however, this new line-shape method of analysis made the whole process much faster (Table 3).
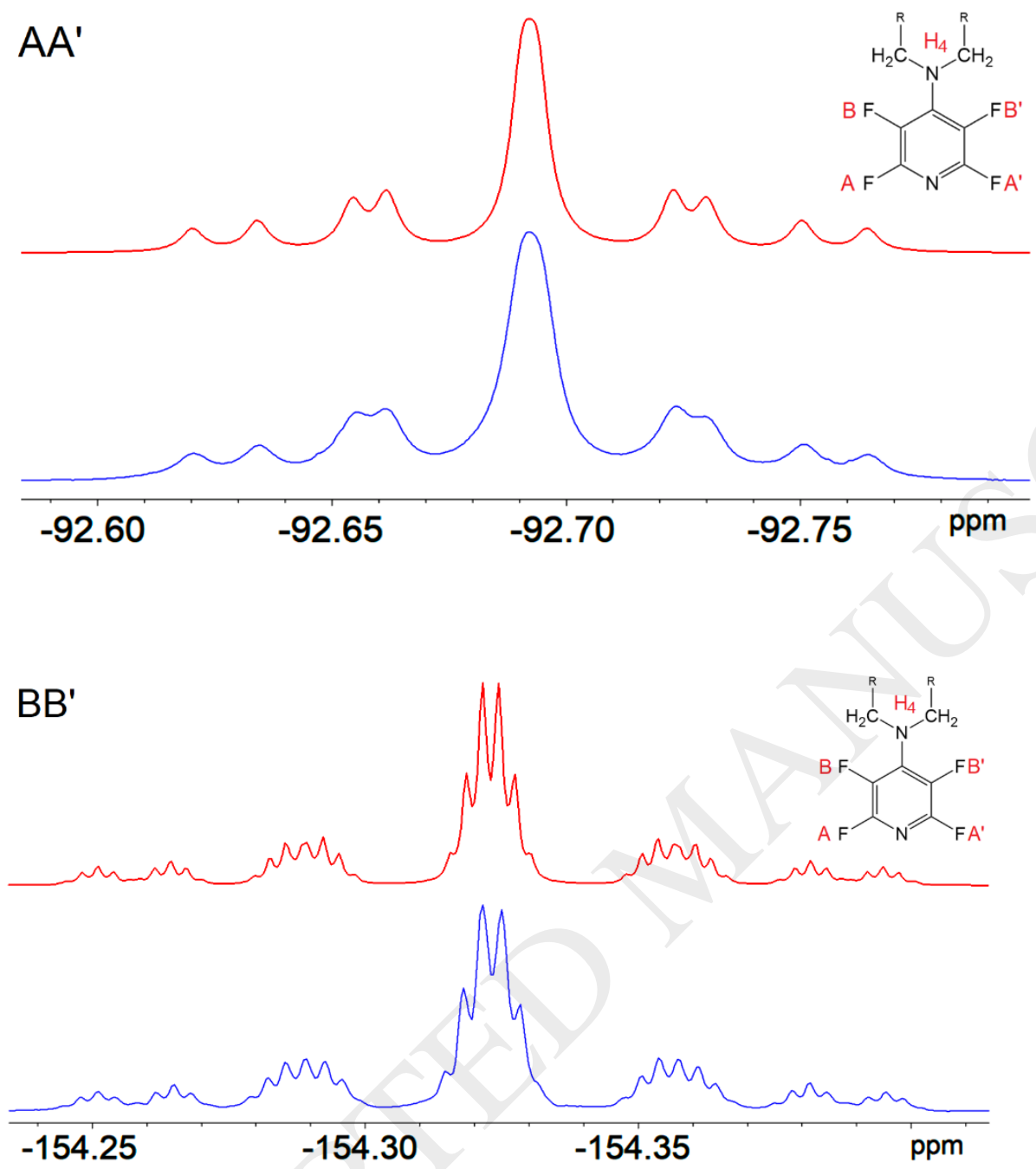

Figure 6. Tetrafluoro-4-(morpholino)pyridine: ${ }^{19} \mathrm{~F}$ NMR multiplets for ortho-AA' and meta-BB' fluorine atoms, ANATOLIA optimised (upper) and experimental (lower). (500 $\mathrm{MHz}$ for ${ }^{1} \mathrm{H}$ ).

Optimisation results in different sign for the ortho- ${ }^{4} \mathrm{~J} A A^{\prime}$ coupling, negative with SpinWorks and positive with ANATOLIA, whilst the size of the coupling has a significant influence on the appearance of the spectrum, the sign has little effect in this example. The method of Abraham [41] shows that ${ }^{4} \mathrm{~J}_{\mathrm{FF}} A A^{\prime}$ in $\mathrm{NH}_{2}$-substituted pentafluorobenzene is $-2.6 \mathrm{~Hz}$ and ${ }^{4} \mathrm{~J}_{\mathrm{FF}}$ $\mathrm{BB}^{\prime}$ is $+4.98 \mathrm{~Hz}$ and that ${ }^{4} \mathrm{~J}_{\mathrm{FF}} \mathrm{AA}^{\prime}$ in $\mathrm{NH}_{2}$-substituted difluorobenzene [48] is $+6.4 \mathrm{~Hz}$ [49 50] and ${ }^{4} \mathrm{~J}_{\mathrm{FF}} \mathrm{BB}^{\prime}$ is $+12.43 \mathrm{~Hz}[51]$, however the couplings are different in the pyridine aromatic system with ${ }^{4} J_{F F}\left(A A^{\prime}\right)=-14 \mathrm{~Hz}[52]$, in excellent agreement with this analysis. The broad nature of the $A A^{\prime}$ multiplet is not evident in the $B B^{\prime}$ multiplet, and this effect is attributed to a combination of the proximity of the ${ }^{14} \mathrm{~N}$ quadrupolar nucleus (spin =1) [53 54] and a possible long-range $\mathrm{F}-\mathrm{H}$ coupling (less than $0.5 \mathrm{~Hz}$ ). These data were used as a foundation to 
analyse the ${ }^{13} \mathrm{C}$ multiplets in the carbon spectrum and the ${ }^{19} \mathrm{~F}-{ }^{13} \mathrm{C}$-satellite signals in the fluorine spectrum.

\begin{tabular}{|c|c|c|c|}
\hline Spin-System AA'BB'-H ${ }_{4}$ & ANATOLIA labels & SpinWorks & ANATOLIA \\
\hline A & FreqA & $-92.7 \mathrm{ppm}$ & $-92.7 \mathrm{ppm}$ \\
\hline$A^{\prime}$ & FreqA' & $-92.7 \mathrm{ppm}$ & $-92.7 \mathrm{ppm}$ \\
\hline $\mathrm{B}$ & FreqB & $-154.32 \mathrm{ppm}$ & $-154.32 \mathrm{ppm}$ \\
\hline $\mathrm{B}^{\prime}$ & FreqB' & $-154.32 \mathrm{ppm}$ & $-154.32 \mathrm{ppm}$ \\
\hline${ }^{4} J_{F F} A A^{\prime}$ & $\mathrm{J} 1,2$ & $14.60 \mathrm{~Hz}$ & $-14.583 \mathrm{~Hz}$ \\
\hline${ }^{3} J_{F F} A B=A^{\prime} B^{\prime}$ & $\mathrm{J} 1,3$ & $-22.88 \mathrm{~Hz}$ & $-23.188 \mathrm{~Hz}$ \\
\hline${ }^{5} J_{F F} A B^{\prime}=A^{\prime} B$ & J 1,4 & $21.28 \mathrm{~Hz}$ & $21.028 \mathrm{~Hz}$ \\
\hline${ }^{4} J_{F F} B B^{\prime}$ & J 3,4 & $-4.737 \mathrm{~Hz}$ & $+5.069 \mathrm{~Hz}$ \\
\hline${ }^{5} J_{F H} B-H_{4}$ & $\mathrm{~J} 3,6$ & $1.57 \mathrm{~Hz}$ & $1.50 \mathrm{~Hz}$ \\
\hline
\end{tabular}

Table 3. Analysed NMR chemical shifts and scalar couplings $(\mathrm{Hz})$ constants extracted from the experimental ${ }^{19} \mathrm{~F}$ NMR spectrum of tetrafluoro-4-(morpholino)pyridine acquired using a $500 \mathrm{MHz}$ spectrometer, $\mathrm{AA}^{\prime} \underline{\mathrm{BB}}{ }^{\prime}-\mathrm{H}_{4}$ spin-system with symmetry. $\Delta \delta \mathrm{AA}^{\prime}=0.0 \mathrm{~Hz}, \Delta \delta \mathrm{BB}^{\prime}=0.0$ $\mathrm{Hz}$.

\subsection{Tetrafluoro-4-(morpholino)pyridine: Analysis of the ${ }^{13} \mathrm{C}$ NMR Isotopomers.}

The existence of a single ${ }^{13} \mathrm{C}$ atom in the ortho-( $\left.\mathrm{AA}^{\prime}\right)$ or meta-(BB') positions of the pyridine ring changes the spin-system and symmetry is broken. This subtle effect changes the charge density around the directly attached ${ }^{13} \mathrm{C}$-fluorine atom, thus the chemical shift of previously equivalent fluorine atoms can now be different such that $\delta A \neq \delta A^{\prime}$, the influence of this isotope effect also propagates over several bonds allowing $\delta B \neq \delta B^{\prime}$. Once symmetry is broken, there is no longer a strict requirement for ${ }^{3} J A B=A^{\prime} B^{\prime}$ or ${ }^{5} A^{\prime} B^{\prime}=A^{\prime} B$. Therefore, each ${ }^{13} \mathrm{C}$ isotopomer is a distinct and different molecule and spin-system, which can have unique and distinct chemical shifts and coupling constants from one another. Experimental evidence of this isotopomer effect is clearly visible in the carbon spectrum where ortho- ${ }^{13} \mathrm{C}-$ $\mathrm{AA}^{\prime} \mathrm{BB}^{\prime}$ and meta- ${ }^{13} \mathrm{C}-\mathrm{AA}^{\prime} \mathrm{BB}^{\prime}$ have completely different multiplets, and for the ${ }^{13} \mathrm{C}$-satellites in the ${ }^{19} \mathrm{~F}$ spectrum (Figure 7) where meta- ${ }^{13} \mathrm{C}-\mathrm{AA}^{\prime} \underline{B B}^{\prime}$ is asymmetric. Each isotopomer subspectrum requires an individual analysis in order to extract $\Delta \delta{ }^{19} \mathrm{~F}$ shifts and coupling constants, which traditionally has involved the investment of significant time, but the speed advantage of ANATOLIA helps make these analyses more accessible.

The signal-to-noise of the carbon spectrum is 1600 for protonated $\mathrm{CH}_{2}$ carbons and 74 for the $\mathrm{C}-\mathrm{F}$ aromatic carbons, and this allows some of the low-intensity second-order signals to be visible as shown by an asterix in Figure 7. Improved $\mathrm{S} / \mathrm{N}$ is highly desirable to facilitate line-shape analysis method as some very small intensity signals are absent from the experimental spectrum, particularly the ortho- ${ }^{13} \mathrm{C}-\mathrm{AA}^{\prime}$ at $145 \mathrm{ppm}$. The appearance of the carbon-fluorine multiplets for ortho- and para-carbons are completely different, the isotopomer that is responsible for the ortho-carbon(A $\left.A^{\prime}\right)$ signal at $145 \mathrm{ppm}$ approximates to a doublet-of-triplets, and the isotopomer that is responsible for the meta-carbon(BB') signal at $135 \mathrm{ppm}$ is a doublet-of-multiplets. This significant difference in appearance of the 
multiplets is mainly as a result of the complex interplay of $\delta A \neq \delta A^{\prime}$ and $\delta B \neq \delta B^{\prime}$ for the fluorine chemical shifts and ${ }^{4} \mathrm{~J} A \mathrm{~A}^{\prime}$ and ${ }^{4} \mathrm{JBB}^{\prime}{ }^{19} \mathrm{~F}$ couplings, but subtle differences in the spectrum are also linked to the size and sign of the ${ }^{1} \mathrm{~J}-{ }^{4} \mathrm{~J} C F$ couplings $\left({ }^{1} \mathrm{~J}_{\mathrm{CF}}\right.$ is negative), these multiplets are deceptively simple in appearance. Here, assign-iterate methods may have an advantage as the importance of low-intensity second-order signals can be prioritised during analysis, whereas the line-shape method may "miss" low-intensity signals. The ${ }^{19} \mathrm{~F}$ coupling data was utilised as a starting point and ${ }^{19} \mathrm{~F}$ chemical shift difference optimised, then the influence of the couplings and ${ }^{19} \mathrm{~F} \Delta \delta$ explored simultaneously, and finally the influence of ${ }^{1} \mathrm{~J}$ ${ }^{4} \mathrm{~J}$ CF couplings was investigated. The chemical shift difference $\Delta \delta$ of the fluorine atoms $A A^{\prime}$ was found to be $15.0 \mathrm{~Hz}$ and $\mathrm{BB}^{\prime}=11.8 \mathrm{~Hz}$ for the ortho- ${ }^{13} \mathrm{C}$-isotopomer, and $\mathrm{AA}^{\prime}$ is $12.2 \mathrm{~Hz}$ and $\mathrm{BB}^{\prime}=27.0 \mathrm{~Hz}$ for the meta $^{-13}{ }^{13} \mathrm{C}$-isotopomer (Table 4).
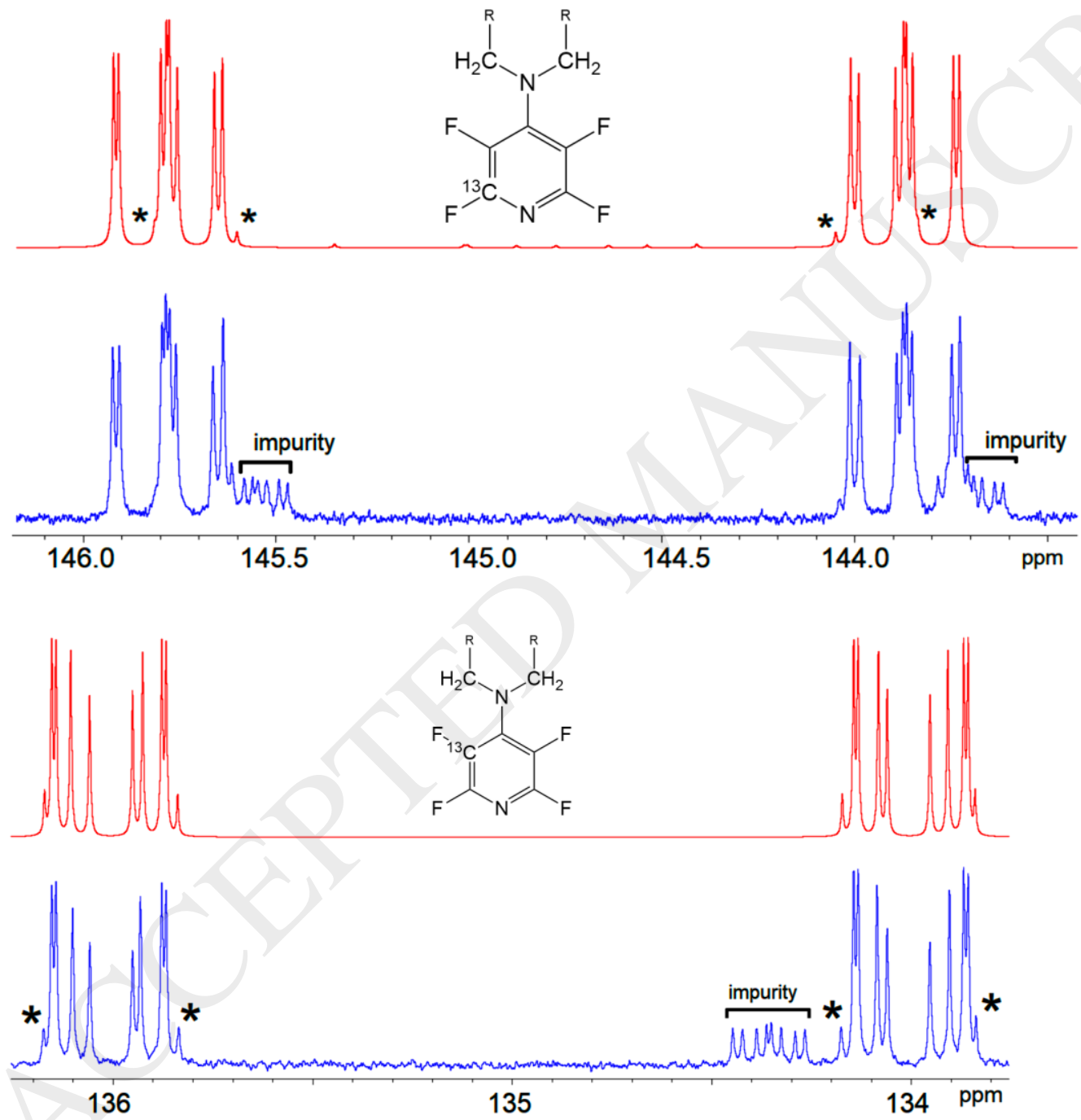

Figure 7. Tetrafluoro-4-(morpholino)pyridine: ${ }^{13} \mathrm{C}$ NMR spectra of tetrafluoro-4-(morpholino)pyridine showing C-F doublets and fine coupling structure. Ortho- ${ }^{13} \mathrm{C}-\mathrm{AA}^{\prime}$ isotopomer at $145 \mathrm{ppm}$ and meta${ }^{13} \mathrm{C}-\mathrm{BB}^{\prime}$ isotopomer at $135 \mathrm{ppm}$. Asterix highlights the second-order transitions that are highly dependent on ${ }^{19} \mathrm{~F} \Delta \delta \mathrm{AA}^{\prime}$ and $\Delta \delta \mathrm{BB}^{\prime}$ chemical shift differences, and on the size of ${ }^{4} \mathrm{~J}_{\mathrm{FF}} \mathrm{AA}^{\prime},{ }^{4} \mathrm{~J}_{\mathrm{FF}} \mathrm{BB}^{\prime}$ and ${ }^{1} \mathrm{~J}-{ }^{4} \mathrm{~J} C-\mathrm{F}$ couplings. 


\begin{tabular}{|c|c|c|c|c|c|c|}
\hline Spin labels & GIAO/Spinspin & GIAO/Mixed & ANATOLIA & ANATOLIA & ANATOLIA & ANATOLIA \\
\hline & $6-311^{++} G^{* *}$ & $6-311^{++} G^{* *}$ & Ortho- ${ }^{13} \underline{C} \mathrm{AA}^{\prime}$ & Meta $-{ }^{13} \underline{C}$ BB' & ${ }^{19} \underline{F} \mathrm{AA}^{\prime}{ }^{13} \mathrm{C}$ Satellites & ${ }^{19} \underline{\mathrm{F}} \mathrm{BB}^{\prime}{ }^{13} \mathrm{C}$ Satellites \\
\hline$A$ & \multirow[t]{2}{*}{-90.38 ppm } & \multirow[t]{2}{*}{-90.60 ppm } & $-92.7 \mathrm{ppm}$ & $-92.7 \mathrm{ppm}$ & -92.7 ppm & $-92.7 \mathrm{ppm}$ \\
\hline$A^{\prime}$ & & & $\Delta \delta=15.0 \mathrm{~Hz}$ & $\Delta \delta=12.2 \mathrm{~Hz}$ & $\Delta \delta=15.0 \mathrm{~Hz}$ & $\Delta \delta=10.83 \mathrm{~Hz}$ \\
\hline$B$ & \multirow[t]{2}{*}{$-165.39 \mathrm{ppm}$} & \multirow[t]{2}{*}{$-168.16 p p m$} & $-154.32 \mathrm{ppm}$ & $-154.32 \mathrm{ppm}$ & $-154.32 \mathrm{ppm}$ & $-154.32 \mathrm{ppm}$ \\
\hline$B^{\prime}$ & & & $\Delta \delta=11.8 \mathrm{~Hz}$ & $\Delta \delta=27.2 \mathrm{~Hz}$ & $\Delta \delta=11.8 \mathrm{~Hz}$ & $\Delta \delta=27.21 \mathrm{~Hz}$ \\
\hline & & & 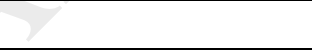 & & & \\
\hline${ }^{13} \mathrm{C}$ A ortho & $168.05 \mathrm{ppm}$ & 149.46 ppm & $144.8 \mathrm{ppm}$ & & & \\
\hline${ }^{13} \underline{\mathrm{C}} \mathrm{B}$ meta & $154.1 \mathrm{ppm}$ & $135.8 \mathrm{ppm}$ & & $135.0 \mathrm{ppm}$ & & \\
\hline${ }^{13} \mathrm{C}$ C para & $156.04 \mathrm{ppm}$ & $136.93 \mathrm{ppm}$ & & & & \\
\hline Meta-C-F A $\left({ }^{2} \mathrm{~J}_{\mathrm{CF}}\right)$ & 24.7 & 29.11 & & 29.53 & & -24.42 \\
\hline Meta-C $-\mathrm{F} \mathrm{A}^{\prime}\left({ }^{4} \mathrm{~J}_{\mathrm{CF}}\right)$ & 5.4 & 4.96 & & 5.16 & & -3.43 \\
\hline Meta $-\underline{C}-\mathrm{F} \mathrm{B}\left({ }^{1} \mathrm{~J}_{\mathrm{CF}}\right)$ & -309.2 & -317.00 & & -252.62 & & -252.40 \\
\hline Meta- $\underline{\mathrm{C}}-\mathrm{F} \mathrm{B}^{\prime}\left({ }^{3} \mathrm{~J}_{\mathrm{CF}}\right)$ & -1.5 & -1.44 & & 1.30 & & 1.37 \\
\hline Ortho- $\underline{C}-\mathrm{F} \mathrm{A}\left({ }^{1} \mathrm{~J}_{\mathrm{CF}}\right)$ & -300.4 & 309.24 & -239.35 & & -239.27 & \\
\hline Ortho- $\underline{-}-\mathrm{F} \mathrm{B}^{\prime}\left({ }^{4} \mathrm{~J}_{\mathrm{CF}}\right)$ & 2.0 & 1.99 & 1.78 & & 1.8 & \\
\hline$A A^{\prime}\left({ }^{4} J_{F F}\right)$ & -13.6 & -13.07 & -14.5 & -14.5 & -14.5 & -15.26 \\
\hline$A B\left({ }^{3} J_{F F}\right)$ & -18.9 & -12.8 & -22.8 & -23.8 & -22.8 & -21.03 \\
\hline$A B^{\prime}\left({ }^{5} J_{F F}\right)$ & 25.1 & 24.40 & 21.3 & 23.3 & 21.3 & 23.86 \\
\hline$A^{\prime} B\left(J_{F F}\right)$ & 25.1 & 24.40 & 21.3 & 23.3 & 21.3 & 23.86 \\
\hline$A^{\prime} B^{\prime}\left({ }^{3} J_{F F}\right)$ & -18.9 & -12.8 & -22.8 & -23.8 & -22.8 & -21.03 \\
\hline $\mathrm{BB}^{\prime}\left({ }^{4} J_{\mathrm{FF}}\right)$ & 10.6 & 9.84 & 5.5 & -5.0 & -5.5 & -5.15 \\
\hline $\mathrm{B}-\mathrm{H}_{4}{ }^{*}$ & 0.41 & 9.0 & 1.35 & 1.35 & 1.35 & 1.3 \\
\hline
\end{tabular}

Table 4. Tetrafluoro-4-(morpholino)pyridine: Chemical shifts and coupling constants from spectral analysis and ab initio calculations Gaussian03 B3-LYP/6-311++G** nmr=spinspin and Gaussian-09 B3-LYP/6-311++G** nmr=mixed [43]. ${ }^{19} \mathrm{~F}$ referenced to $\mathrm{CFCl}_{3}$ at $0.0 \mathrm{ppm}\left(\mathrm{C}_{6} \mathrm{~F}_{6}\right.$ at -161.8 ppm). Experimental NMR ${ }^{13} \mathrm{C}$ referenced to TMS at $0.0 \mathrm{ppm}$ (calculations ${ }^{13} \mathrm{C}$ referenced to $\mathrm{C}_{6} \mathrm{H}_{6}$ at 128 ppm). * average of four couplings. 


\subsection{Tetrafluoro-4-(morpholino)pyridine: Analysis of the ${ }^{19} \mathrm{~F}-{ }^{13} \mathrm{C}$ Satellite Signals Isotopomers ortho- ${ }^{13} \mathrm{C}-\mathrm{AA}^{\prime} \mathrm{BB}^{\prime}$ and $m e t a-{ }^{13} \mathrm{C}-\mathrm{AA}^{\prime}{ }^{\mathrm{BB}}$ '.}

A simple way to visualise the fact that parameters are significantly different in the ${ }^{12} \mathrm{C}$ and each ${ }^{13} \mathrm{C}$ isotopomer is to look at the stark differences in the ${ }^{19} \mathrm{~F}-{ }^{12} \mathrm{C}$ multiplet and its ${ }^{19} \mathrm{~F}-{ }^{13} \mathrm{C}$ satellite isotopomer. Here, there are significant differences in the multiplets for the $A A^{\prime}$ and $\mathrm{BB}^{\prime}$ fluorine signals. Whilst the largest coupling is the ${ }^{1} \mathrm{~J}_{\mathrm{CF}}=-252.4 /-238.6 \mathrm{~Hz}$ is simple to estimate from the experimental spectrum, the interplay of the ${ }^{2} \mathrm{~J}-{ }^{4} \mathrm{~J} C F$ couplings is much less obvious, but the result is to make the fine structure of the satellite doublet asymmetric (Figure 8). Only when the ${ }^{2} \mathrm{~J}-{ }^{4} \mathrm{~J} C F$ couplings are included in the calculation can accurate values for ${ }^{19} \mathrm{~F} \Delta \delta \mathrm{AA}^{\prime}, \Delta \delta \mathrm{BB}^{\prime},{ }^{4} \mathrm{~J}_{\mathrm{FF}} \mathrm{AA}^{\prime}$ and ${ }^{4} \mathrm{~J}_{\mathrm{FF}} \mathrm{BB}^{\prime}$ be calculated. Accurate results were obtained with symmetry retained for $A B=A^{\prime} B^{\prime}$ and $A B^{\prime}=A^{\prime} B$, with no meaningful improvements in fitting obtained when symmetry was reduced $\left(A B \neq A^{\prime} B^{\prime}\right.$ and $\left.A B^{\prime} \neq A^{\prime} B\right)$. The data extracted from the ${ }^{13} \mathrm{C}$ spectrum matches the data extracted from the ${ }^{19} \mathrm{~F}$ spectrum ${ }^{19} \mathrm{~F}-{ }^{13} \mathrm{C}$-satellites, as expected.
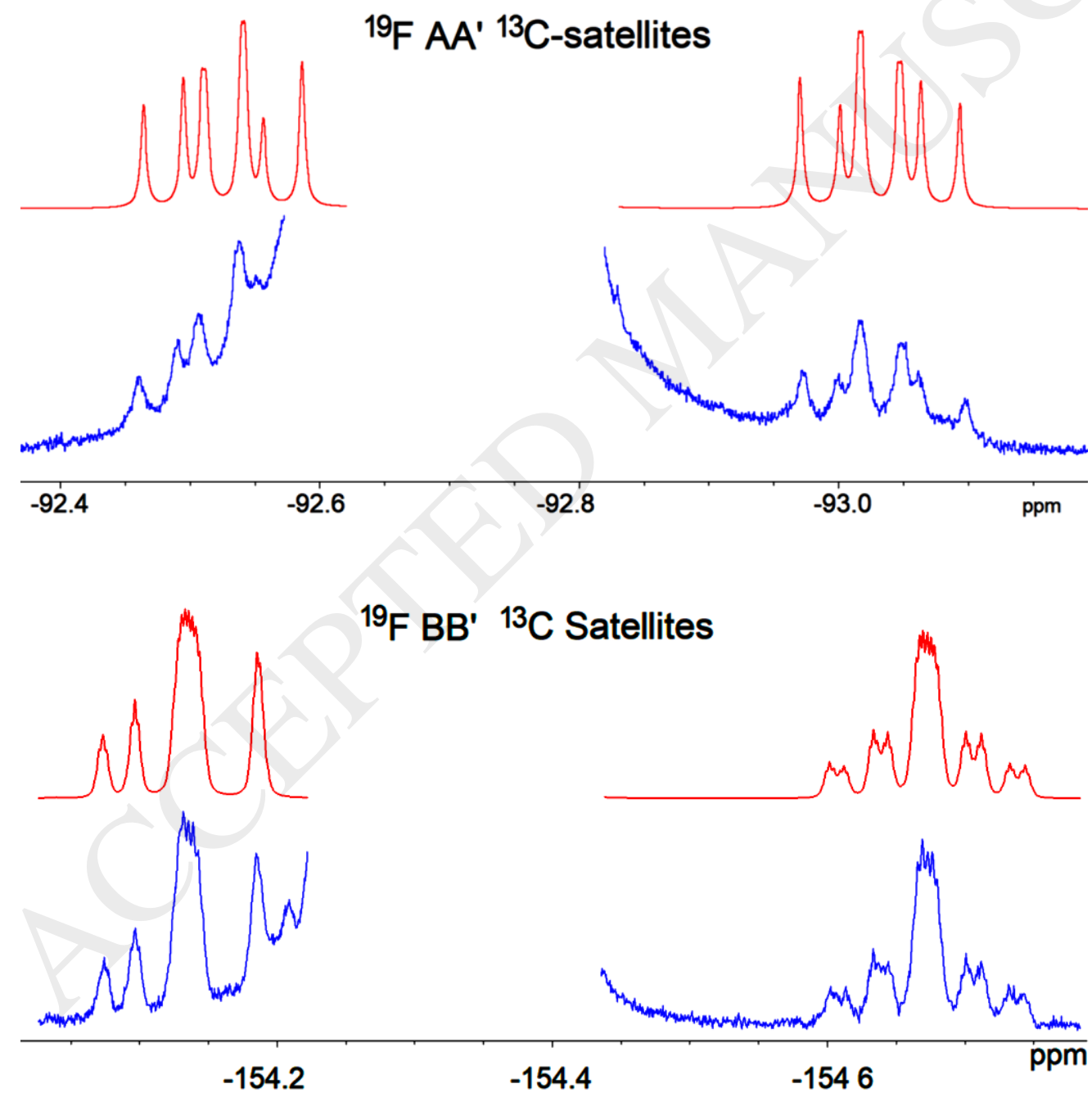

Figure 8. Tetrafluoro-4-(morpholino)pyridine: ${ }^{19} \mathrm{~F}$ NMR spectrum showing ortho- ${ }^{13} \mathrm{C}-\mathrm{AA}$ ' (symmetric) and $m e t a-{ }^{13} \mathrm{C}-\mathrm{BB}^{\prime}$ (asymmetric) satellite multiplets (the central $99 \%{ }^{19} \mathrm{~F}-{ }^{12} \mathrm{C}$ multiplet has been removed for clarity). 


\section{Conclusion}

Many excellent computational methods have been published over the years, but ANATOLIA is one of the most user-friendly, fast, robust and accurate tools available. This program is eminently applicable to synthetic bench chemists, who should be encouraged to use this program. Pentafluorobenzene is a well characterised and very simple molecule that produces a series of 'unusual' multiplets in the ${ }^{19} \mathrm{~F}$ and ${ }^{13} \mathrm{C}$ spectra that do not conform to first-order multiplets and from which it is difficult to extract the coupling constants using traditional assign-iterate methods. ANATOLIA produced an excellent result within 10 seconds for the complete ${ }^{19} \mathrm{~F}$ spectrum using inaccurate input data. The ${ }^{13} \mathrm{C}$ spectrum and ${ }^{19} \mathrm{~F}$ spectrum with ${ }^{19} \mathrm{~F}-{ }^{13} \mathrm{C}$-satellite multiplets required a few minutes of calculation time and some manual intervention to yield accurate coupling and ${ }^{19} \mathrm{~F} \Delta \delta$ chemical shift values and nJ $_{\mathrm{CF}}$ coupling constants.

For the real-world example of tetrafluoro-4-(morpholino)pyridine only the ${ }^{1} \mathrm{H},{ }^{13} \mathrm{C}$ and ${ }^{19} \mathrm{~F}$ NMR spectra were used, without recourse to complex and bespoke 2D methods that are rarely made accessible to bench chemists. The ANATOLIA program was able to rapidly analyse the symmetric ${ }^{19} \mathrm{~F} \mathrm{AA}^{\prime} \mathrm{BB}^{\prime}$ spin-system to provide accurate chemical shifts and coupling constants. The complex second-order multiplets in the ${ }^{13} \mathrm{C}$ spectrum and ${ }^{19} \mathrm{~F}-{ }^{13} \mathrm{C}$ satellites in the ${ }^{19} \mathrm{~F}$ NMR spectrum displayed deceptively simple multiplets that were analysed in a straightforward manner with some manual intervention. These constraints were applied sequentially in order to allow accurate spectral values to be obtained from inaccurate input values: particularly for ${ }^{19} \mathrm{~F}^{4} \mathrm{~J}_{\mathrm{AA}^{\prime}},{ }^{4} \mathrm{~J}_{\mathrm{BB}^{\prime}}$, and chemical shift differences $\triangle \delta A A^{\prime}$ and $\Delta \delta \mathrm{BB}^{\prime}$ in the ${ }^{19} \mathrm{~F}-{ }^{13} \mathrm{C}$ satellites and ${ }^{13} \mathrm{C}$ multiplets. $A b$ initio $\mathrm{GIAO}$ shielding values provided a useful starting point for the ${ }^{19} \mathrm{~F}$ and ${ }^{13} \mathrm{C}$ chemical shifts and most coupling constants, but not for the ${ }^{4} \mathrm{JBB}^{\prime}$ coupling.

\section{Conflicts of interest}

There are no financial or intellectual conflicts of interest to declare. The authors are not connected to the ANATOLIA team.

Orcid

Mark Edgar : $\quad$ 0000-0002-8579-1088

George Weaver: $\quad$ 0000-0002-1316-1941

\section{Acknowledgements}

Thanks to Prof. Ray Abraham for continued support and encouragement and to Prof. Martin Grootveld for helpful discussions. Access to the latest F-H probes from Bruker and JEOL was very useful to confirm coupling interactions and assignments. Loughborough University for the purchase of the Bruker Avance-I $500 \mathrm{MHz}$ NMR spectrometer (SRIF2) and JEOL ECS 400 $\mathrm{MHz}$ NMR spectrometer, and the purchase of the Gaussian-03 PC licence, and Dr. Pooja 
Journal of Fluorine Chemistry

Goddard (née Panchmatia) who purchased the high-power computer site-licence for Gaussian-09.

\section{Experimental}

ANATOLIA was downloaded from GitHub [55]. Windows-10 set up comprises of adding two files to the TOPSPIN directory, an AU program called ANATOLIA to "TopSpin/exp/stan/nmr/au/src/user", and the executable file also called ANATOLIA to "TopSpinHomeDirectory/prog/anatolia". There after two files are required in the NMR data folder, "Parameters_start" that contains coupling constants and chemicals shifts, and "InputData" that contains the spin-system labels, folder-path, and list of parameters that need to be optimised.

Pentfluorobenzene: ${ }^{1} \mathrm{H},{ }^{1} \mathrm{H}\left\{{ }^{19} \mathrm{~F}\right\},{ }^{19} \mathrm{~F}\left\{{ }^{1} \mathrm{H}\right\},{ }^{13} \mathrm{C}\left\{{ }^{1} \mathrm{H}\right\},{ }^{13} \mathrm{C}\left\{{ }^{19} \mathrm{~F}\right\}$, DEPT, COSY,${ }^{1} \mathrm{H}-{ }^{19} \mathrm{~F}$ NOESY, ${ }^{1} \mathrm{H}-{ }^{13} \mathrm{C}-$ $\mathrm{HMQC}$ and ${ }^{19} \mathrm{~F}-{ }^{13} \mathrm{C}-\mathrm{HMQC}$ spectra were recorded using JEOL ECS-400 MHz, JEOL ECZ-500 or Bruker Avance-I $500 \mathrm{MHz}$ NMR spectrometers, using $5 \mathrm{~mm}$ NMR tubes. Samples were prepared using $\sim 10 \mathrm{mg}$ of pentafluorobenzene for dilute solutions and $\sim 100 \mathrm{mg}$ for concentrated solutions to acquire excellent signal-to-noise for ${ }^{13} \mathrm{C}$ spectra, dissolved in a $0.70 \mathrm{ml}$ volume of $\mathrm{CDCl}_{3}$ obtained from Apollo-UK. High quality $5 \mathrm{~mm}$ diameter NMR tubes purchased from Norell were used at both 400 and $500 \mathrm{MHz}$ operating frequencies.

Tetrafluoro-4-(morpholino)pyridine: ${ }^{1} \mathrm{H},{ }^{19} \mathrm{~F},{ }^{13} \mathrm{C}\left\{{ }^{1} \mathrm{H}\right\}$ and ${ }^{13} \mathrm{C}$ spectra were recorded using a Bruker Avance-I $500 \mathrm{MHz}$ NMR spectrometers, using $5 \mathrm{~mm}$ NMR tubes. Samples were prepared using 10 mg of tetrafluoro-4-(morpholino)pyridine for dilute solutions and 100 $\mathrm{mg}$ for concentrated solutions to acquire excellent signal-to-noise for ${ }^{13} \mathrm{C}$ spectra, dissolved in a $0.70 \mathrm{ml}$ volume of $\mathrm{CDCl}_{3}$ obtained from Apollo-UK. High quality $5 \mathrm{~mm}$ diameter NMR tubes purchased from Norell.

${ }^{1} \mathrm{H}$ NMR spectra were typically recorded using the small flip-angle pulse program with $\mathrm{P}_{90}=$ $15 \mu$ s covering a sweep width of $20.7 \mathrm{ppm}$ with $128 \mathrm{~K}$ time domain data points giving an acquisition time of 8 seconds, Fourier-transformed using $256 \mathrm{~K}$ data points and referenced to an internal TMS standard at $\delta=0.00 \mathrm{ppm}$.

${ }^{19} \mathrm{~F}$ NMR spectra were typically recorded using the small flip-angle pulse program with $\mathrm{P}_{90}=$ $8 \mu$ s covering a sweep width of 37 ppm with $256 \mathrm{~K}$ time domain data points giving an acquisition time of 7.5 seconds, a line-narrowing gaussian function was applied then Fourier-transformed using $512 \mathrm{~K}$ data points and referenced to an external $\mathrm{CFCl}_{3}$ standard at $\delta=0.00$ ppm (ref: $\mathrm{C}_{6} \mathrm{~F}_{6}$ at $\left.-161.8 \mathrm{ppm}\right)$.

${ }^{13} \mathrm{C}$ NMR spectra were obtained on a spectrometer operating at $100.6 \mathrm{MHz}(400 \mathrm{MHz}$ equivalent for ${ }^{1} \mathrm{H}$ ) or $125 \mathrm{MHz}\left(500 \mathrm{MHz}\right.$ equivalent for ${ }^{1} \mathrm{H}$ ), also employing a $5 \mathrm{~mm}$ highresolution broad-band probe. The pulse program employs a direct $30^{\circ}$ pulse on carbon with waltz16 decoupling during acquisition, and a relaxation delay of 1.00 second. Spectra were recorded over a sweep width of $250 \mathrm{ppm}(25,252 \mathrm{~Hz})$ with $64 \mathrm{~K}$ time domain datapoints, giving an acquisition time of 1.30 seconds. A single exponential function of 1.00 was applied, and spectra were Fourier-transformed using $128 \mathrm{~K}$ datapoints and referenced to an internal 
Journal of Fluorine Chemistry

tetramethylsilane (TMS) standard at $\delta=0.00 \mathrm{ppm}$. For improved digital resolution in the ${ }^{13} \mathrm{C}$ spectrum, data was also acquired without ${ }^{1} \mathrm{H}$ decoupling, but using an acquisition time of 6.5 seconds.

Gaussian-03 calculations were run on a i7 PC using 1-core and 8Gb of memory, structures optimised using B3-LYP/6-31G* and GIAO NMR parameters using B3-LYP/6-311++G** $\mathrm{nmr}=$ spinspin. Gaussian-09 calculations were run on an iMac using 4-cores and 8Gb of memory, structures were optimised using B3-LYP/6-31G* and GIAO NMR parameters using B3-LYP/6-311++G** nmr=spinspin, and B3-LYP/6-31G* nmr=mixed. 
Journal of Fluorine Chemistry

References

[1] Y. Zhou, J. Wang, Z. Gu, S. Wang, W. Zhu, J. L. Aceña, V. A. Soloshonok, K. Izawa, H. Liu, Next Generation of Fluorine-Containing Pharmaceuticals, Compounds Currently in Phase II-III Clinical Trials of Major Pharmaceutical Companies: New Structural Trends and Therapeutic Areas, Chem. Rev. 116 (2016) 422-518.

[2] J. Wang, M. Sánchez-Roselló, J. L. Aceña, C. del Pozo, A. E. Sorochinsky, S. Fustero, V. A. Soloshonok, H. Liu, Fluorine in pharmaceutical industry: fluorine-containing drugs introduced to the market in the last decade (2001-2011), Chem. Rev. 114 (2014) 2432-2506. doi: $10.1021 / \mathrm{cr} 4002879$

[3] H. Chen, S. Viel, F. Ziarelli, L. Peng, ${ }^{19}$ F NMR: A Valuable Tool for Studying Biological Events, Chem. Soc. Rev. 42 (2013) 7971-7982.

[4] T. D. Alger, H. S. Gutowsky, Solvent and Temperature Dependence of NMR Spectral Parameters in 2-Fluoropyridine Solutions, J. Chem. Phys. 48 (1968) 4625-4632. doi.org/10.1063/1.1668038

[5] R. L. Lichter, R. E. Wasylishen, Fluoropyridines. Carbon-13 Chemical Shifts and Carbon-Fluorine Coupling Constants, J. Am. Chem. Soc. 97 (1975) 1808-1813.

[6] W. A. Thomas G. E. Griffin, The NMR spectra of some fluorinated pyridine derivatives, Org. Mag. Res. 2 (1970) 503-525.

[7] R. J. Spear, D. A. Forsyth, G. A. Olah, Carbon-Fluorine Spin-Spin Coupling in Carbocations, J. Am. Chem. Soc. 98 (1976) 2493-2500.

[8] W. S. Brey L. W. Jaques H. J. Jakobsen, $\mathrm{A}^{13} \mathrm{C}\left\{{ }^{1} \mathrm{H}\right\}$ double resonance study of the signs of ${ }^{1} \mathrm{H}-{ }^{19} \mathrm{~F}$ and ${ }^{13} \mathrm{C}-{ }^{19} \mathrm{~F}$ spin coupling constants in fluorobenzenes and 2-fluoropyridine, Org. Mag. Res. 12 (1979) 243-246.

[9] J. W. Emsley, L. Phillips, V. Wray, Fluorine Coupling Constants, Progress in NMR Spectroscopy, 10 (1976) 83-756. Pergamon Press. Printed in Great Britain.

[10] H. J. Jakobsen, W. S. Brey, ${ }^{15} \mathrm{~N}-{ }^{19} \mathrm{~F}$ spin coupling mechanism in 2-fluoropyridine studied by selective population transfer in ${ }^{15} \mathrm{~N}$ nuclear magnetic resonance, Chem. Commun. 11 (1979) 478-479.

[11] J. R. Nanny, C. A. L. Mahaffy, The use of ${ }^{19} \mathrm{~F}$ NMR spectra of fluoropyridines and related compounds to verify the Isstatisticalrs substituent chemical shift values of fluoroarenes, J. Fluorine Chem. 68 (1994) 181-200.

[12] K. A. M. Ampt, R. L. E. G. Aspers, M. Jaeger, P. E. T. J. Geutjes, M. Honing, S. S. Wijmenga, Application of fluorine NMR for structure identification of steroids, J. Mag. Res. 49 (2011) 221 230.

[13] W. R. Dolbier Jr., Guide to Fluorine NMR for Organic Chemists ( $2^{\text {nd }}$ edition), Wiley, 2016. ISBN: 978-1-118-83108-3.

[14] B. C. Percival, M. Grootveld, M. Gibson, Y. Osman, M. Molinari, F. Jafar, T. Sahota, M. Martin, F. Casanova, M. L. Mather, M. Edgar, J. Masania, P. B. Wilson, Low-Field, Benchtop NMR Spectroscopy as a Potential Tool for Point-of-Care Diagnostics of Metabolic Conditions: Validation, Protocols and Computational Models, High-Throughput 8 (2019) 2-33. https://doi.org/10.3390/ht8010002.

[15] M. Grootveld, B. C. Percival, M. Gibson, Y. Osman, M. Edgar, M. Molinari, M. L. Mather, F. Casanova, P. B. Wilson, Progress in low-field benchtop NMR spectroscopy in chemical and biochemical analysis, Anal. Chim. Acta; available online 23 February 2019. https://doi.org/10.1016/ 
[16] R. J. Abraham, The Analysis of High-Resolution NMR Spectra, Elsevier Publishing Co., New York, 1971. DOI: 10.1021/ed049pA603.

[17] J. M. Granda, L. Donina, V. Dragone, D. L. Long, L. Cronin, Controlling an organic synthesis robot with machine learning to search for new reactivity, Nature 559 (2018) 377-381.

[18] P. M. Richardson, A. J. Parrott, O. Semenova, A. Nordon, S. B. Duckett, M. E. Halse, SABRE hyperpolarization enables high-sensitivity ${ }^{1} \mathrm{H}$ and ${ }^{13} \mathrm{C}$ benchtop NMR spectroscopy, Analyst, 143 (2018) 3442-3450.

[19] M.Edgar, B. C. Percival, M. Gibson, P. B. Wilson, M. Grootveld, Benchtop NMR Spectroscopy and Spectral Analysis of the cis- and trans-Stilbene Products of the Wittig Reaction, submitted to J. Chem. Educ. 2019.

[20] K. L. Yearty, J. T. Sharp, E. K. Meehan, D. R. Wallace, D. M. Jackson, R. W. Morrison, Implementation of Pico-Spin Benchtop NMR Instruments into Organic Chemistry Teaching Laboratories through Spectral Analysis of Fischer Esterification Products, J. Chem. Educ. 94 (2017) 932-935.

[21] M. F. Isaac-Lam, Analysis of Bromination of Ethylbenzene Using a $45 \mathrm{MHz}$ NMR Spectrometer: An Undergraduate Organic Chemistry Laboratory Experiment, J. Chem. Educ. 91 (2014) 1264-1266.

[22] H. J. Reich, WinDNMR: Dynamic NMR Spectra for Windows, J. Chem. Educ. 72 (1995) 1086.

[23] NMRSIM Copyright (c) 1999 by Bruker Analytik GmbH. Part No. H9171.

[24] H. Hogben, M. Krzystyniak, G. Charnock, P. Hore, I. Kuprov, Spinach - A software library for simulation of spin dynamics in large spin systems, J. Magn. Reson. 208 (2011) 179-194. doi.org/10.1016/j.jmr.2010.11.008.

[25] SpinWorks 3.1, Copyright (C) 2009, Kirk Marat, University of Manitoba.

[26] P. Vidal, N. Esturau, T. Parella, J. F. Espinosa, A Simple Method for Measuring Long-Range 1H13C Coupling Constants in Organic Molecules, J. Org. Chem. 72 (2007) 3166-3170.

[27] V. V. Krishnamurthy, Excitation-Sculptured Indirect-Detection Experiment (EXSIDE) for LongRange CH Coupling-Constant Measurement, J. Mag. Reson. Series A 121 (1996) 33-41.

[28] M. Kurz, P. Schmieder, H. Kessler, An Efficient Method for Determining Heteronuclear LongRange Couplings with Hetero-nuclei in Natural Abundance, Angew. Chem. Int. Ed. 30 (1991) 1329-1331.

[29] C. Griesinger, O.W. Sorensen, R.R. Ernst, Practical aspects of the E-COSY technique. Measurement of scalar spin-spin coupling constants in peptides, J. Magn. Reson. 75 (1987) 474-492.

[30] K. A. M. Ampt, R. L. E. G. Aspers, P. Dvortsak, R. M. van der Werf, S. S. Wijmenga, M. Jaeger, Determination of size and sign of hetero-nuclear coupling constants from $2 \mathrm{D}{ }^{19} \mathrm{~F}-{ }^{13} \mathrm{C}$ correlation spectra, J. Mag. Reson., 215 (2012) 27-33.

[31] R. L. E. G. Aspers, K. A. M. Ampt, P. Dvortsak, M. Jaeger, S. S. Wijmenga, Fluorine detected 2D NMR experiments for the practical determination of size and sign of homonuclear $\mathrm{F}-\mathrm{F}$ and heteronuclear $\mathrm{C}-\mathrm{F}$ multiple bond J-coupling constants in multiple fluorinated compounds, J. Mag. Reson. 231 (2013) 79-89.

[32] W. P. Aue, J. Karhan, R. R. Ernst, Homonuclear broad-band decoupling and 2-dimensional Jresolved NMR spectroscopy, J. Chem. Phys. 64 (1976) 4226-4227.

[33] J. A. Aguilar, S. Faulkner, M. Nilsson, G. A. Morris, Pure Shift ${ }^{1} \mathrm{H}$ NMR: A Resolution of the Resolution Problem?, Angew. Chem., Int. Ed. 49 (2010) 3901-3903.

[34] M. Foroozandeh, G. A. Morris, M. Nilsson, PSYCHE Pure Shift NMR Spectroscopy, Chem. Eur. J. 24 (2018) 1-14.

[35] D. A. Cheshkov, K. F. Sheberstov, D. O. Sinitsyn, V. A. Chertkov, ANATOLIA: NMR software for spectral analysis of total lineshape, Magn. Reson. Chem. 56 (2018) 449-457. 
[36] M. Edgar, G. Weaver, in preparation for, Magn. Reason. Chem. 2019.

[37] I. J. Lawrencen, High-resolution Fluorine Magnetic Resonance Spectra of some Pentafluoropheny Derivatives, J. Chem. Soc. (1965) 1117-1120.

[38] A. Haloui, E. Haloui, $r_{\alpha}$ Structures of partially oriented pentafluorobenzenes $C_{6} F_{5} X(X=H, C l, I)$ as determined from ${ }^{19} \mathrm{~F}$ NMR spectra with ${ }^{13} \mathrm{C}$ satellites, Magn. Reson. Chem. 49 (2011) 717724.

[39] B. Aldridge, G. De Luca, M. Edgar, S. J. Edgar, J. W. Emsley, M. I. C. Furby, M. Webster, The structure of 2,2'-difluorobiphenyl in solid crystalline and liquid crystalline phases, J. Liquid Crystals 24 (1998) 569-581. https://doi.org/10.1080/026782998207046.

[40] M. Edgar, J. W. Emsley, M. I. C. Furby, General Features of the X Part of an ABX Spin System in Isotropic and Liquid Crystalline Phases as Illustrated by the ${ }^{13} \mathrm{C}\left\{{ }^{1} \mathrm{H}\right\}$ Spectra of 2,2'Difluorobiphenyl, J. Mag Res. 128 (1997) 105-113. https://doi.org/10.1006/jmre.1997.1225.

[41] R. J. Abraham, M. Ashley Cooper, A re-investigation of ${ }^{4} J_{\mathrm{FF}}$ and ${ }^{5} J_{\mathrm{FF}}$ nuclear spin-spin couplings in substituted benzenes, a novel conformational tool, Phys. Chem. Chem. Phys. 18 (2016) 15822-15827.

[42] Gaussian 03, Revision C.02, M. J. Frisch, G. W. Trucks, H. B. Schlegel, G. E. Scuseria, M. A. Robb, J. R. Cheeseman, J. A. Montgomery, Jr., T. Vreven, K. N. Kudin, J. C. Burant, J. M. Millam, S. S. Iyengar, J. Tomasi, V. Barone, B. Mennucci, M. Cossi, G. Scalmani, N. Rega, G. A. Petersson, H. Nakatsuji, M. Hada, M. Ehara, K. Toyota, R. Fukuda, J. Hasegawa, M. Ishida, T. Nakajima, Y. Honda, O. Kitao, H. Nakai, M. Klene, X. Li, J. E. Knox, H. P. Hratchian, J. B. Cross, V. Bakken, C. Adamo, J. Jaramillo, R. Gomperts, R. E. Stratmann, O. Yazyev, A. J. Austin, R. Cammi, C. Pomelli, J. W. Ochterski, P. Y. Ayala, K. Morokuma, G. A. Voth, P. Salvador, J. J. Dannenberg, V. G. Zakrzewski, S. Dapprich, A. D. Daniels, M. C. Strain, O. Farkas, D. K. Malick, A. D. Rabuck, K. Raghavachari, J. B. Foresman, J. V. Ortiz, Q. Cui, A. G. Baboul, S. Clifford, J. Cioslowski, B. B. Stefanov, G. Liu, A. Liashenko, P. Piskorz, I. Komaromi, R. L. Martin, D. J. Fox, T. Keith, M. A. AlLaham, C. Y. Peng, A. Nanayakkara, M. Challacombe, P. M. W. Gill, B. Johnson, W. Chen, M. W. Wong, C. Gonzalez, J. A. Pople, Gaussian, Inc., Wallingford CT, 2004.

[43] M. Edgar, G. W. Weaver, in preparation 2019.

[44] A. V. Buevich, J. Saurí, T. Parella, N. De Tommasi, G. Bifulco, R. T. Williamson, G. E. Martin, Enhancing the utility of $1 \mathrm{JCH}$ couplings constants in structural studies through optimized DFT analysis, Chem. Commun. 2019, accepted manuscript. DOI:10.1039/C9CC02469G

[45] M. Filatova, D. Cremer, Calculation of spin-densities within the context of density functional theory. The crucial role of the correlation functional, J. Chem. Phys. 123 (2005) 124101, 1-7. https://doi.org/10.1063/1.2047467

[46] J. S. Martin, A. R. Quirt, NMR spectra of symmetric molecules. I. The spin Hamiltonian for twofold symmetry, J. Magn. Reson. 5 (1971) 318-327.

[47] SpinWorks 3.1, Copyright (C) 2009, Kirk Marat, University of Manitoba.

[48] E. A. Cohen, A. J. R. Bourne, S. L. Manatt, On the NMR Spectra of Pentafluorobenzene, J. Mag. Res. 1 (1969) 436-449.

[49] R. J. Abraham, D. B. Macdonald, E. S. Pepper, Nuclear magnetic resonance spectra of fluorobenzenes II. Effect of substituents on the meta and para fluorine-fluorine coupling constants, J. Am. Chem. Soc. 90 (1968) 147-153.

[50] V. Wray, D. N. Lincoln, The additivity of substituent effects upon J(FF) in polysubstituted fluorobenzenes: An update, Org. Mag. Res. 9 (1977) 155-156.

[51] J. F. Busby, M.Sc. thesis, University of Liverpool, 1970.

[52] "Fluorine Coupling Constants", Pergamon Press. Printed in Great Britain. by J. W. Emsley, L. Phillips, V. Wray, Progr. NMR Spectrosc. 10 (1976) 83-756. 
Journal of Fluorine Chemistry

[53] G.J. Jenks, NMR Investigation of the Nitrogen Quadrupole Coupling Constant in Liquid Samples, J. Chem. Phys. 54 (1971) 658-663.

[54] J.P. Kintzinger, J.M. Lehn, Nuclear relaxation and molecular properties Part I. ${ }^{14} \mathrm{~N}$ nuclear quadrupolar relaxation and ${ }^{1} \mathrm{H}$ line shapes in nitrogen-containing heterocycles, J. Mol. Phys. 14 (1968) 133-145.

[55] https://github.com/dcheshkov/ANATOLIA 